\title{
Mixture Preparation and Combustion Variability in a Spray-Guided DISI Engine
}

\author{
J. Serras-Pereira and P.G. Aleiferis \\ University College London, UK
}

\author{
D. Richardson and S. Wallace \\ Jaguar Advanced Powertrain Engineering, Coventry, UK
}

Copyright @ 2007 SAE International

\section{ABSTRACT}

In an attempt to study the numerous contributors towards cyclic variations in combustion in a direct injection spark ignition engine, simultaneous high-speed imaging of fuel injection and flame growth are undertaken on a crankangle resolved basis in a single-cylinder optical research engine. Batches of images from 100 consecutive cycles are acquired for all conditions with synchronised incylinder pressure logging. The engine is motored and fired at stoichiometric conditions at 1500 RPM under part-load and wide-open-throttle conditions (0.5-1.0 bar intake pressure), with injection timing set early in the intake stroke to promote homogeneous mixture formation with a centrally mounted multi-hole injector. Liquid impingement is observed on the cylinder walls and on the piston crown with early intake injection and multiple injection strategies are employed in an attempt to reduce impingement and alter mixture preparation and subsequent combustion. The effects are investigated for iso-octane and pump-grade gasoline at engine coolant temperatures of 50 and $90{ }^{\circ} \mathrm{C}$. Gasoline sprays showed severe deformation and partial collapse of the individual spray plumes at $90{ }^{\circ} \mathrm{C}$, leading to a different mixture formation process relative to iso-octane, which showed no such effects at this engine temperature. Using multiple fuel injections per cycle, but maintaining the same overall air-to-fuel ratio with single-injection strategies, a significant reduction in direct impingement on the walls was observed, together with different flame growth relative to single injection. These results suggest that injection strategy and type of fuel is playing an important role in the mixture preparation process, even for homogeneous early direct injection, and that different types of multiple-injection strategies alone have the potential to modify significantly in-cylinder phenomena, affect combustion and potentially exhaust emissions.

\section{INTRODUCTION}

In the current automotive industry climate of market and legislative pressure to reduce fuel consumption and produce less polluting spark ignition engines, cycle-bycycle variations in combustion have been identified as one major obstacle for engine optimization [1]. In the past, these have been typically studied for Port Fuel Injection (PFI) engines, e.g. see [2-5], where levels of cyclic variability were high due to the globally lean air-fuel mixtures employed, a strategy used to increase efficiency and reduce fuel consumption. With the advent of Direct Injection Spark Ignition (DISI) engines, the potential to control fuel metering accurately and the 'infinite' number of injection timing strategies available, meant that hopes were high for the ability of DISI engines to improve engine performance and emissions simultaneously. Two different modes of engine operation were immediately identified with this new found flexibility, a 'homogeneous' mode, where fuel is injected early in the intake stroke in order to promote mixing and produce a globally stoichiometric mixture at ignition timing, and a 'stratified' mode, where fuel is injected late in the compression stroke to produce a stratified cloud of close-to- stoichiometric air-fuel mixture around the spark plug at ignition timing but running with an overall globally lean air-fuel ratio. Much of the available research with DISI engines in recent years has concentrated on optimizing the stratified mode for low and part-load operation [6] but this has so far proved to be more challenging than was initially expected and significant research activity continues in this area [7-10]. However, there is evidence to suggest that there is still plenty of scope to improve the homogeneous mode of operation [11-14], particularly with respect to unburnt hydrocarbon emissions resulting from direct fuel impingement on incylinder surfaces $[15,16]$, and from a driveability point of view to improve engine smoothness and performance, all of which are affected by cyclic variability.

The injector technology used in DISI engines has evolved over the last ten years from single-hole outwardopening injectors, to 'pressure-swirl' atomizers and is now entering a phase of multi-hole injectors, partially as a result of their successful use in Diesel engines, but also as there is a need to more accurately control spray 
directionality, be it either for stratified or homogeneous operation. Although the general advantages and disadvantages of most available DISI engine technologies have been documented earlier [17], and some work exists for stratified engine operation with multi-hole injectors [18], there is a noticeable lack of experimental data under realistic operating conditions for the homogeneous mode of mixture preparation. In particular for the latter, the effects of fuel type and injection strategy on spray formation and combustion have not been studied in detail.

The current work seeks to examine the performance of state-of-the-art DISI multi-hole injector technology and its potential contribution to cyclic combustion variations by:

- Characterizing the effects of operating conditions, namely engine load and operating engine-coolant temperature on spray development and variability in a motoring and firing engine for two fuel types, a multi-component commercial gasoline, as well as a single-component fuel, iso-octane, which is typically used for studies of mixture preparation and combustion in optical engines.

- Investigating the effect of injection strategies, in particular comparing single-injection and multipleinjections strategies for homogeneous mode of engine operation, as a method of affecting mixture preparation and combustion.

- Carrying out cycle-by-cycle analysis of spray and flame parameters relative to in-cylinder pressure parameters to link observed spray effects to flame growth behavior.

In order to study such interactions, a single-cylinder optical DISI engine was used to perform simultaneous hispeed imaging of the fuel spray and flame growth, as well as acquisition of in-cylinder pressure.

\section{EXPERIMENTAL ARRANGEMENT}

\section{OPTICAL ENGINE}

Experiments were carried out with a 4-stroke singlecylinder DISI engine built by Ford (US) and adapted using a prototype cylinder head supplied from Jaguar Advanced Powertrain Engineering. The 4-valve engine has similar bore and stroke geometry to that of a production V8 as outlined in Table 1. It should be noted here that in this paper $0^{\circ}$ Crank Angle (CA) corresponds to intake Top Dead Centre (TDC) and crank-angle timings will be mainly presented with respect to that as After intake TDC (ATDC).

A variety of optical access configurations are possible for this engine, mainly using:

\section{- A piston crown window}

- A full quartz cylinder liner
- A semi-optical liner set-up with a short quartz liner $(\sim 1 / 4$ stroke $)$ that sits on a metal liner ( $\sim 3 / 4$ stroke $)$

- A triangular pent-roof window

Table 1. Optical Engine Specifications.

\begin{tabular}{|l|l|}
\hline Engine Base Type & Jaguar V8 \\
\hline Cycle & 4 -Stroke \\
\hline Cylinders & 1 \\
\hline Valves & 2 Intake, 2 Exhaust \\
\hline Bore & $89.0 \mathrm{~mm}$ \\
\hline Stroke & $90.3 \mathrm{~mm}$ \\
\hline Compression Ratio & $11.15: 1$ \\
\hline Maximum Speed & 2500 RPM \\
\hline Valve Timings & IVO $24^{\circ}$, IVC $274^{\circ}$, EVO $476^{\circ}$, EVC $6^{\circ}$ \\
\hline
\end{tabular}

The different imaging views possible with these arrangements are described in detail later in this paper.

Fuel Injection System: The fuel injection system is comprised of a 'static piston' pneumatic high-pressure pump using the cylinder area multiplier effect so that a 40:1 (demand:supply) ratio of fluid pressure is available. Thus, compressed air is supplied at $\sim 4$ bar to the pump via an in-house designed electronic regulator with filtering to produce 150 bar fluid pressure on the high pressure line to the injector. There is a $2 \mu \mathrm{m}$ filter on the pressure side with a 150 bar check valve in series. The check valve stops backflow under the static-piston reversal stroke which could otherwise reduce supply pressure by up to 10 bar during this period. With the check valve installed, the reduction in line pressure during stroke reversal occurs only due to the injected liquid volume, which results in a gradual 3-4 bar maximum temporary drop in line pressure with minimal line pressure fluctuations.

Fuel Injector: The injector used is a vertical centrally mounted prototype with a 6-hole nozzle in a close spacing arrangement with the spark plug. The nozzle holes are $0.5 \mathrm{~mm}$ in diameter at the exit and essentially consist of two groups of three nozzle holes. The six nozzle holes have different injection angles producing the spray pattern illustrated in Figure 1, where plumes 1 and 6 pass around the spark plug. There is an initial delay before fuel is seen at the injector tip, governed by the injector driver used. For the present tests, liquid fuel was always first seen at the injector tip $300 \mu s$ After Start Of Injection (ASOI) (i.e. after the rising edge of the trigger pulse sent to the injector driver). For further details on the injector, the reader is directed to $[19,20]$. The manufacturer of the injector cannot be identified due to confidentiality agreements. 

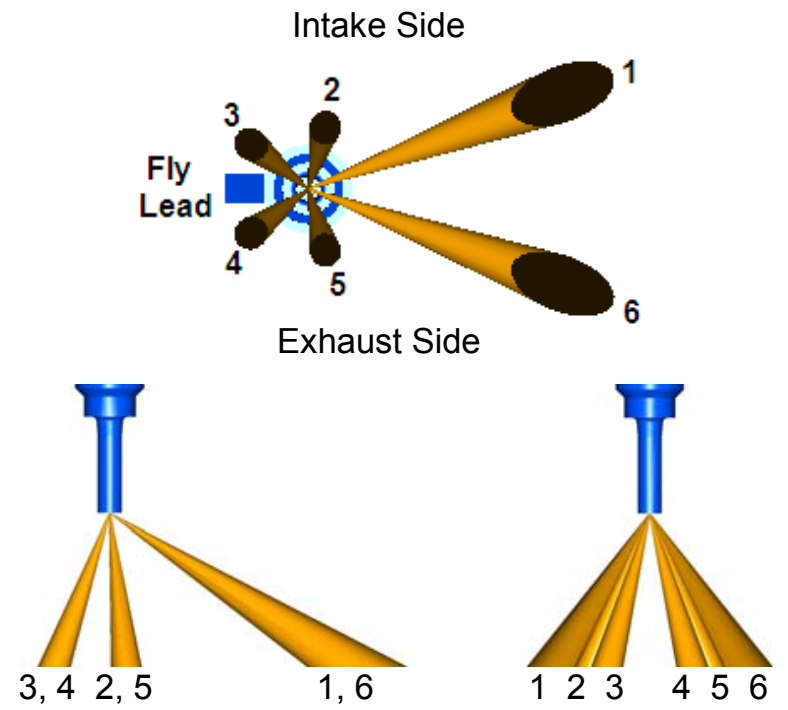

Figure 1. Orientation of the Injector Spray Plumes.

Ignition System: The ignition system is a single coil-onplug type, using a shared $12 \mathrm{~V}, 25 \mathrm{~A}$, DC power supply. A spark-plug with a thin laser-welded platinum-tip central electrode, J-type ground electrode and cone insulator was used (NGK-R). The dwell time was kept constant at $4 \mathrm{~ms}$ following manufacturers' instructions for a typical ignition energy of the order $35-40 \mathrm{~mJ}$. The final electrode orientation with the spark plug tightened is determined by the thread in the cylinder head and the actual location of the welded ground electrode relative to the plug thread. This is apparently random for different production plugs but is known to have an effect on combustion [2, 21, 22]. Therefore, for the work presented here, the same spark plug orientation was used in all the experiments with the electrode pointing towards the exhaust valves $\sim 165^{\circ}$ along an axis passing between the intake and exhaust valves (as seen in images later in this paper).

\section{OPERATING CONDITIONS}

Engine and Dynamometer Arrangement: The engine was motored at $1500 \mathrm{RPM}$ using a $30 \mathrm{~kW}$ AC dynamometer running on digital software interface. The baseline operating conditions used are given in Table 2. The engine was equipped with two optical encoders. One of the encoders was mounted on the intake camshaft and the other on the crankshaft, both of type Leine-Linde 503 , giving $0.2^{\circ} \mathrm{CA}$ resolution. The cycle and crankangle markers were connected to a timing unit (AVL 427 ETU) in order to synchronize the various trigger signals to image and data acquisition systems.

Operating Points: The engine was run under motoring conditions at full load with Wide-Open-Throttle (WOT) (1.0 bar intake pressure), and at part load at the Ford World-Wide-Mapping-Point (WWMP) (0.5 bar intake pressure), or under continuous firing conditions at WWMP (i.e. with no skip-firing). The load was defined by a piezo-resistive pressure sensor in the intake plenum to set the throttle position for the desirable intake pressure. An air/fuel ratio sensor (ECM AFR 1200) was installed in the exhaust manifold. The engine was run with stoichiometric air/fuel ratio (i.e. equivalence ratio $\Phi=1$ ) for the tests presented in the current paper. 100 consecutive cycles of in-cylinder pressure data were acquired after the engine was run for a few seconds to stabilize. Pressure data acquisition was synchronized with simultaneous imaging of the fuel spray and natural flame chemiluminescence.

Table 2. Engine Operating Conditions.

\begin{tabular}{|l|c|}
\hline Engine Speed & 1500 RPM \\
\hline Intake Air Pressure & $0.5,1.0 \mathrm{bar}$ \\
\hline Injection Pressure & $150 \mathrm{bar}$ \\
\hline Firing mode & Continuous, $\Phi=1$ \\
\hline Ignition Timing & $325^{\circ} \mathrm{CA}$ ATDC \\
\hline Fuel & Gasoline, Iso-Octane \\
\hline Engine-Coolant Temperature & $50^{\circ} \mathrm{C}$ and $90^{\circ} \mathrm{C}$ \\
\hline
\end{tabular}

\section{DATA ACQUISITION}

In-Cylinder Pressure: A water-cooled Kistler 6041 pressure transducer was used to record in-cylinder pressure at $0.2^{\circ} \mathrm{CA}$ resolution for batches of 100 cycles. To confirm correct synchronization with imaging sequence on a cycle-by-cycle basis, the spark was deactivated such that the transition from a firing to a nonfiring cycle was correctly identified and matched with flame images and the in-cylinder pressure data. Pressure data acquisition and processing to infer maximum in-cylinder pressure for each cycle $\left(P_{\max }\right)$, crank angle of $P_{\max }\left(\theta_{P \max }\right)$, Indicated Mean Effective Pressure (IMEP), Mass Fraction Burned (MFB), crank angle of $10 \%$ MFB $\left(\theta_{\times b 10 \%}\right)$, etc., was done using LABVIEW and MATLAB software provided by the Internal Combustion Engines Group, University of Oxford, UK.

\section{IMAGE ACQUISITION}

High-Speed Camera: In order to be able to carry out simultaneous imaging of the fuel injection event, as well as the flame kernel growth in the same cycle, a highspeed CMOS camera (Photron APX-RS) was used at a frame rate of $9 \mathrm{kHz}$, corresponding to $1^{\circ} \mathrm{CA}$ between frames at 1500 RPM. This was possible with an image of $640 \times 480$ pixels, giving an optical resolution of $160 \mu \mathrm{m}$ per pixel. The camera memory $(2.15 \mathrm{~GB})$ was partitioned to allow imaging of spray and combustion events in the same cycle by using two different triggers. The camera was coupled to a $60 \mathrm{~mm}$ f 2.8 Nikon lens and the imaging set-up was optimized so that the same settings would suit imaging of the spray and flame. 
Typically 100 cycles were acquired when the camera was used to image either the spray or the flame for each cycle, but when both spray and flame were captured in the same cycle, camera memory restrictions resulted in a user-defined 113 frames being acquired for each event of spray and combustion, giving a total of 226 frames per cycle for 30 consecutive cycles. Acquisition of images for more than 30 or 100 cycles were considered at the time, but the large amount of data (several tens of GB raw images per test) and associated storage issues for subsequent processing (several hundreds of GB of processed data), restricted acquisition of a set that would be perhaps more statistically representative of cyclic variability (say 200-400 cycles). However, this issue is currently being addressed and it is believed that the data set used did not mask any general trends.

High-Speed Laser: Using a divergent spherical lens, the combustion chamber was globally illuminated (by using the full quartz cylinder liner) with a New Wave Nd:YLF laser at $527 \mathrm{~nm}$ entering across the engine in the tumble plane as illustrated in Figure 2. A set of white opaque diffuser boards were used to reduce the laser light intensity getting through to the combustion chamber in order to optimize the Mie-scattering intensities. The laser was a diode-pumped high-repetition double cavity unit (10 kHz maximum Q-switch frequency per cavity) and was run with both heads firing simultaneously at $9 \mathrm{kHz}$ and in-sync with the camera shutter. It was activated at injection timing and switched off after the first 113 camera frames per cycle, in order to allow natural flame imaging on the second camera memory partition.

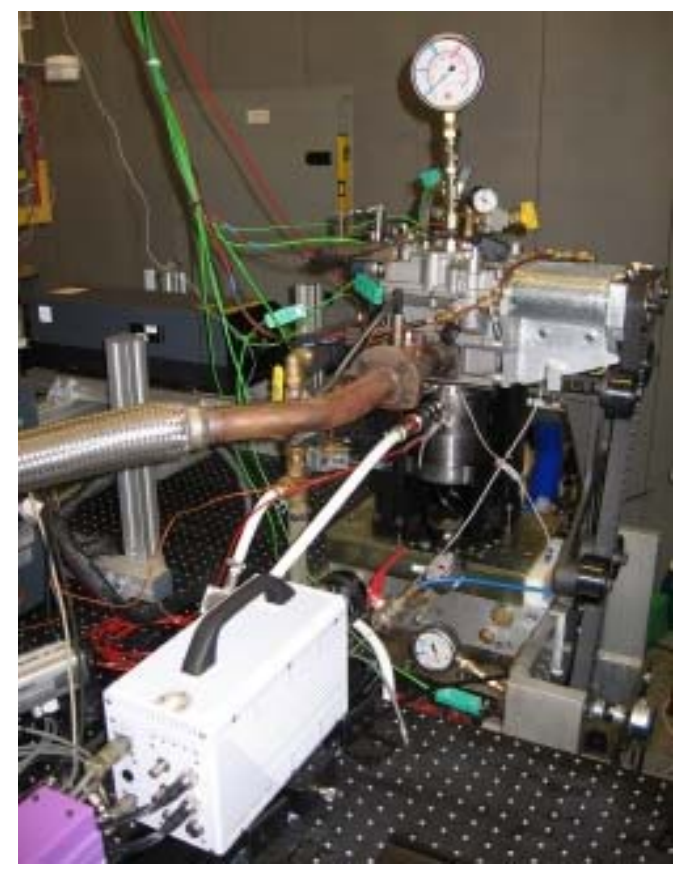

Figure 2. Experimental Set-up for Simultaneous Spray and Flame Imaging through the Piston Crown.

Injection Timing: The injection timings used for homogeneous mode were set quite early in the intake stroke (SOI $60^{\circ} \mathrm{CA} \& 80^{\circ} \mathrm{CA}$ ATDC) in order to maximize the time available for evaporation before ignition. This must however be balanced by the need to avoid excessive liquid impingement on in-cylinder surfaces, particularly on the piston crown, which at $60^{\circ}$ CA ATDC is only $\sim 30 \mathrm{~mm}$ below the head gasket plane for this engine configuration. With initial spray-tip velocities of about $80 \mathrm{~m} / \mathrm{s}$ [19], it is easy to see why liquid impingement is difficult to avoid, particularly at low incylinder pressures. The injection pulse duration was set to $0.78 \mathrm{~ms}\left(\sim 7^{\circ} \mathrm{CA}\right)$ for stoichiometric operation at 1500 RPM and 0.5 bar intake pressure.

Multiple Injections: In order to achieve control over multiple split injections, the AVL timing unit was used with an inbuilt function linking two output trigger channels. The spacing between each split injection is ultimately limited by the response time of the injector and driver. In order to perform comparison between single and multiple injections, a split injection strategy was devised to allow stoichiometric operation comprising of three shorter injections. To keep the time available for evaporation the same before ignition for both injection strategies, the first injection was programmed to start at $60^{\circ} \mathrm{CA}$ ATDC, the second at $70^{\circ} \mathrm{CA}$ and the third at $80^{\circ}$ CA ATDC, with pulse durations of $0.25 \mathrm{~ms}, 0.28 \mathrm{~ms}$ and $0.25 \mathrm{~ms}$ respectively, such that the last injection pulse starts at the same time in the cycle as the single injection (Figure 3). Although the multiple injection strategy has effectively more time available to evaporate before ignition (due its earlier start of injection), using a single injection with such an early SOI would result in significant piston impingement due to the high piston position and the increased momentum of the longer single-injection spray. Thus the case is made that the multiple injection strategy is allowing the engine to operate in a regime that would otherwise incur performance penalties in terms of emissions and combustion stability. It is also interesting to note that the multiple injection strategy resulted in stoichiometric operation using the same overall injection pulse width to that used with the single-injection strategy (0.78 ms).

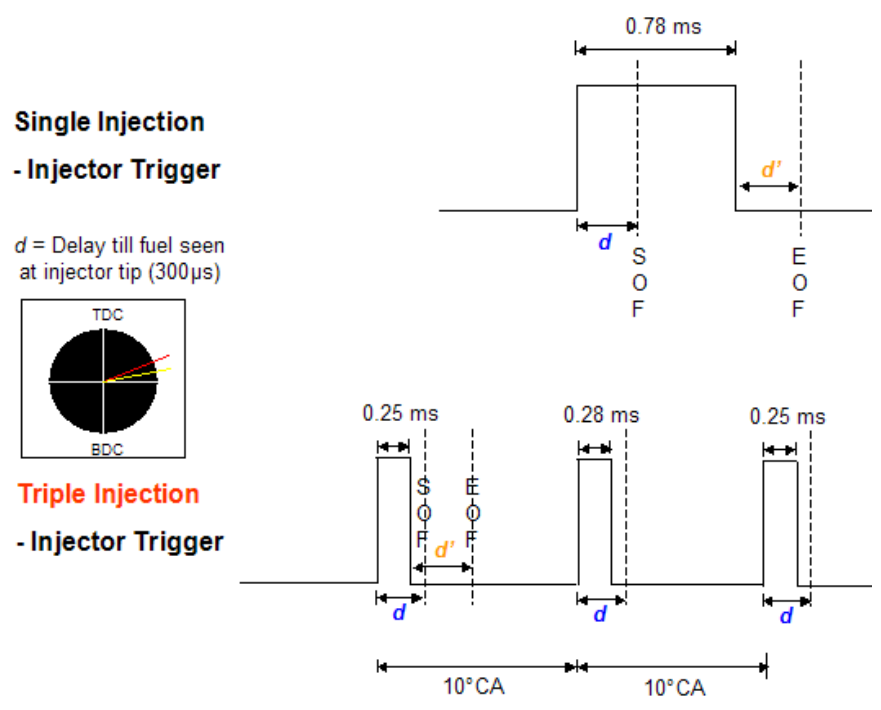

Figure 3. Multiple Injections versus Single Injection. 


\section{MIXTURE PREPARATION SYSTEM OVERVIEW}

Imaging was achieved through the pent-roof window and the full quartz liner as shown in Figure 4. The injector and spark-plug layout were more clearly seen from the piston crown view shown in Figure 5. A third view was also imaged from the exhaust side, although in this case the access was 'cropped' at the head gasket plane as seen in Figure 6.

The spatial information obtained from the view of Figure 4 has been used to investigate spray development and spray-flow interactions on that plane which is particularly relevant since the engine is equipped with a tumbleinducing intake manifold. The view shown in Figure 5 allows a clear simultaneous observation of all six individual spray plumes and was used for most experiments to visualize spray formation and combustion in order to study changes with respect to engine-coolant temperature, fuel type and injection strategies. Figure 6 is used to study possible areas of liquid impingement and global mixture formation quality appraisal, since this view captures the spray side on and is the only plane allowing simultaneous imaging of the three different plume pairs in the vertical axis. This is particularly relevant for investigation of critical locations around the cylinder liner such as the ring reversal region and the piston crown and this in fact a parallel investigation of the reported work but which will be reported upon in a future publication.

Typical spray imaging sequences from each view are shown in Figure 7 with iso-octane fuel and SOI $80^{\circ} \mathrm{CA}$ ATDC under motoring conditions. These indicated that there are a number of factors interacting to produce the final mixture preparation on a cycle-by-cycle basis. Initially, WOT tests were carried out at a modest engine cooling temperature $\left(50^{\circ} \mathrm{C}\right)$ to simulate the cold-to-warm engine transition in the moments after an engine cold start. It was observed that changing the injection timing in the early intake stroke by $20^{\circ} \mathrm{CA}$, between $60^{\circ} \mathrm{CA}$ and $80^{\circ}$ CA ATDC, resulted in a noticeably different spray flow interaction, particularly towards the end of injection, $\sim 11^{\circ} \mathrm{CA}$ ASOI. The effect can be identified even on the tumble plane images of Figure 7. A noticeable curvature of the left-side spray plume can be seen as it passes the intake valve and although the spray is pretty symmetrical in the early stages of injection ( $0-5^{\circ} \mathrm{CA}$ ASOI), by the end of injection (10-15 $\mathrm{CA}$ ASOI) a difference in penetration distances can be seen for the plumes on the intake side compared to the those on the exhaust side. It was difficult to establish categorically whether direct impingement of some of the spray plumes occurs - or would occur - on the intake valves as a result of the injector nozzle layout, e.g. plume 3 (with reference to the earlier designation in Figure 1), mainly due to the fact that high concentration of atomized liquid in the pent-roof was obscuring the view during injection. However, it is believed that this is - or would be - indeed the case, particularly with SOI timings later than $\sim 80^{\circ}$ CA ATDC. For example fuel impingement on the valves has been reported in [23] from a 5-valve single-cylinder optical DISI engine also using a centrally mounted multi-hole injector arrangement.

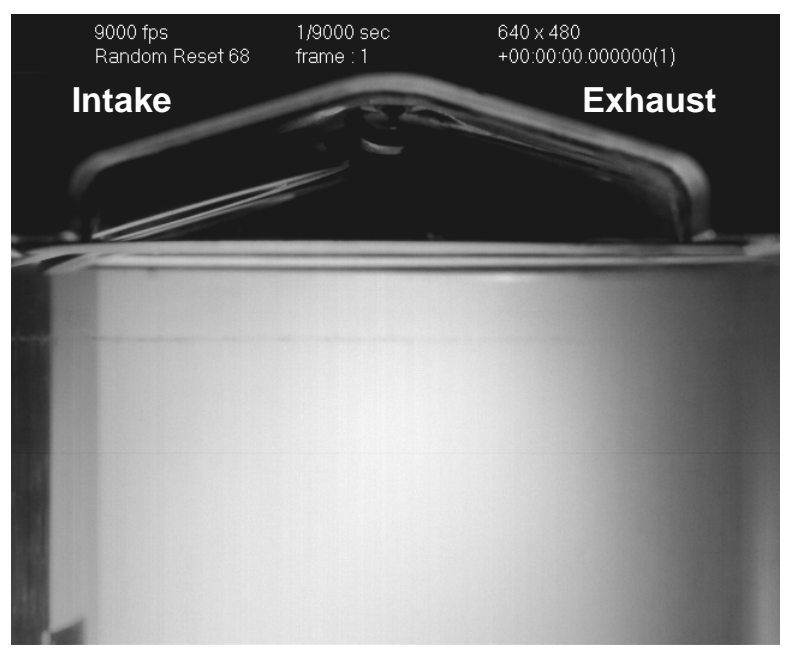

Figure 4. Pent-Roof \& Full Quartz Liner (Tumble View).

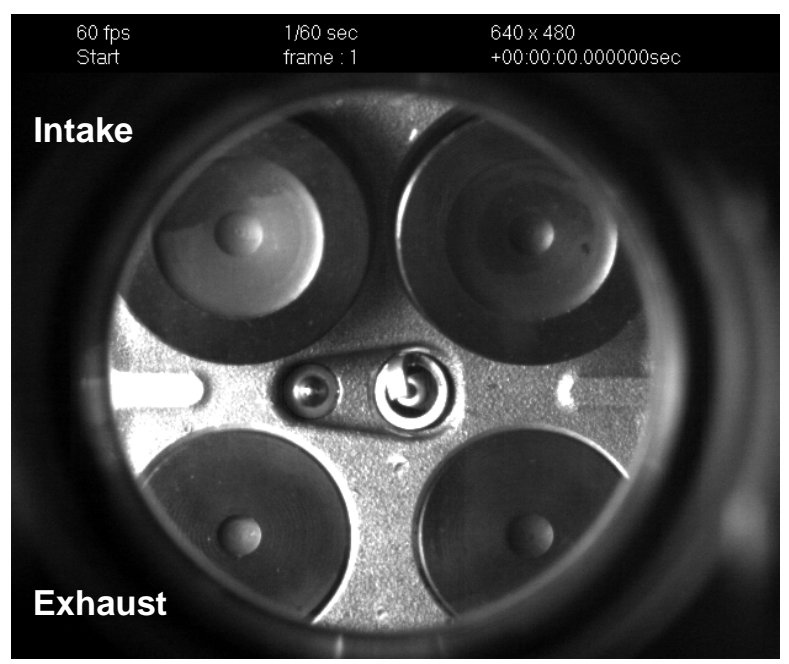

Figure 5. Piston Crown View.

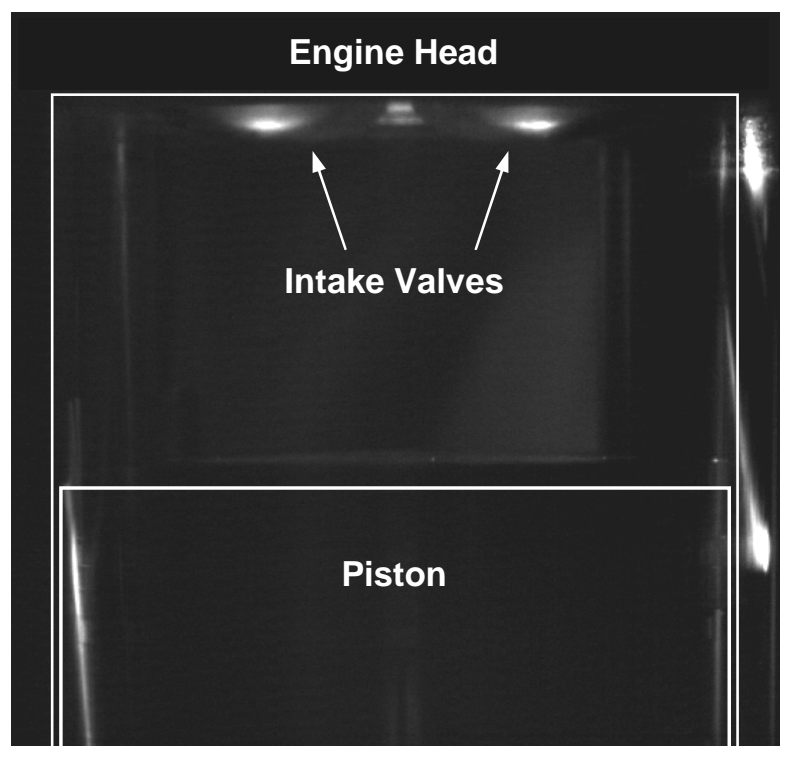

Figure 6. Full Quartz Liner (Exhaust View). 

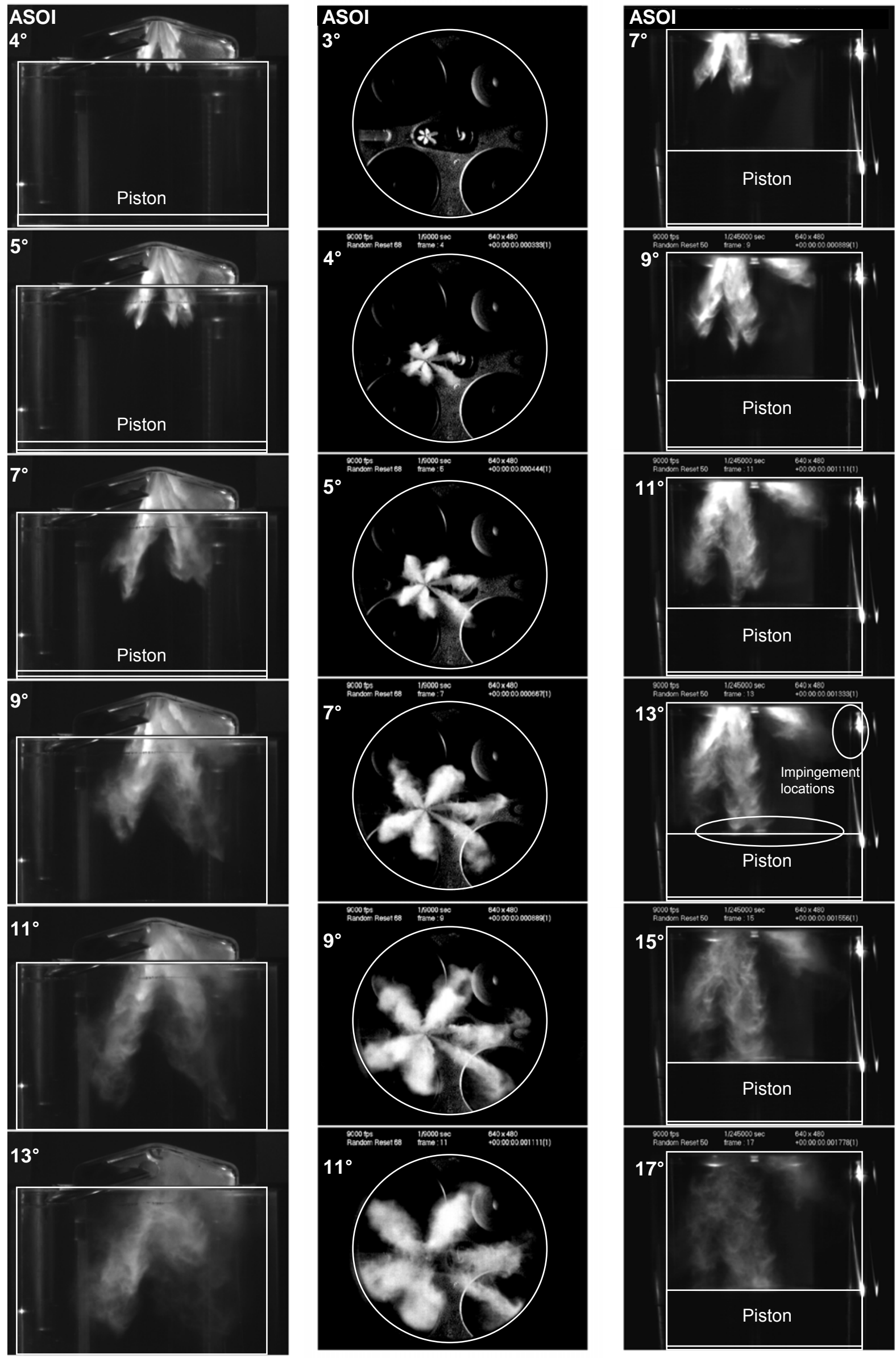

Figure 7. Column 1: Pent-Roof Window and Full Liner (Tumble Plane, WOT); Column 2: Piston-Crown (Swirl Plane, WWMP); Column 3: Full Liner (Exhaust Side, WWMP). 
Under WOT conditions, the spray was not seen to impinge directly on the piston crown for SOI $80^{\circ} \mathrm{CA}$ ATDC. The piston speed towards the end of injection at $93^{\circ} \mathrm{CA}$ ATDC is at its fastest and the result is the spray 'chasing' the piston, an analogy commonly used as a reference to the necessary behavior in early injection DISI engines in order to avoid impingement and associated increased emissions due to reduced mixing efficiency. It was also noticed that around this time (93$97^{\circ} \mathrm{CA}$ ATDC) the leading edges of the spray appear to be suddenly affected by the now established in-cylinder tumble flow and deflected sideways towards the intake side and upwards in the cylinder away from the piston crown, also contributing to the lack of piston impingement. The cross-flow on top of the piston at this point in the cycle has a velocity in excess of $20 \mathrm{~m} / \mathrm{s}$ as shown by Particle Image Velocimetry (PIV) carried out on an identical engine [24] and this compares to spray tip velocities at the same time after SOI measured in an injection rig [19] which have now been substantially reduced due to drag and leading edge evaporation from their initial velocities of $\sim 80 \mathrm{~m} / \mathrm{s}$. The above mentioned flow effects are also observed for SOI $60^{\circ}$ CA ATDC. However, in this case direct piston impingement is seen for the four central plumes due to the higher piston position. The large magnitude of cross-flow velocities immediately after impingement and a hot piston surface are expected to aid film evaporation and result in attenuated effects for combustion in a firing engine.

The other two views seen in Figure 7 correspond to WWMP conditions at the same engine speed (1500 RPM). The main differences are better atomization due to low in-cylinder pressures ( 0.5 bar), but increased spray penetrations resulting in substantially more direct piston impingement, even for SOI $80^{\circ} \mathrm{CA}$ ATDC. Maybe more significantly, impingement is increased on the cylinder liner $\sim 17 \mathrm{~mm}$ below TDC (in the piston ring reversal region) between the intake and exhaust valves, stemming from spray plumes 1 and 6 , which even with reduced injection pulse widths used to attain the same air-fuel ratio (stoichiometric) at this lower engine-load condition, are less affected by the flow past the intake valves than at WOT, which coupled with increased spray penetrations results in increased wall wetting. It should be noted though, that due to illumination of the spray from below, through the piston crown window via the $45^{\circ}$ mirror, the images seen through the piston liner are to some extent limited in spatial resolution close to the cylinder walls since the piston crown is only $65 \mathrm{~mm}$ in diameter (in comparison to the $89 \mathrm{~mm}$ bore) and effectively 'clips' the light available for illumination. Additionally, there is increased optical distortion from the curving cylinder liner close to the walls. Therefore, there is scope for further study through these views to draw more specific conclusions.

The piston crown view allows simultaneous imaging of the six spray plumes and tracking of their interactions with the flow in a time resolved manner that to some extent can provide information about the nature of the intake flow on a cycle-by-cycle basis. It was seen for iso- octane that the 'spark-plug' plumes, i.e. plumes 1 and 6, are immediately affected by the incoming valve jet after injection, and that this results in a deflection of the spray plumes away from the intake side towards the exhaust side as injection progresses. The other plumes (2-5) appear more robust through this view in the early stages of injection. This is mainly attributed to their injection angles which are biased towards to the piston rather than across the pent-roof as is the case for plumes 1 and 6 . This results in a lower area of valve-jet flow acting on the spray plumes which reduces flow interactions in the pentroof for these plumes. The high downward injection momentum of the near-nozzle region also overpowers the incoming flow through the valves and results in a spray pattern with good directionality. The latter cannot be said for the spark-plug spray plumes.

It is only until $\sim 7^{\circ} \mathrm{CA}$ ASOI that some liquid 'separation' is first seen at the spray tips, as leading edge evaporation takes place and air entrainment immediately behind the lead edge apparently produces regions of high and low liquid 'density' seen by alternating areas of higher and lower scattering intensities in the spray. This is also seen in the tumble-plane view, as well as in the exhaust-side view, although the exact mechanisms involved and relative contributions are difficult to identify and describe currently. It appears, as seen in the tumble plane, that spray penetrations are marginally greater for the intake side plumes. It is thought that regions of lower pressure due to the two counter-rotating vortices that are formed under the intake valves and the strong valve jet directed down the cylinder wall towards the piston, as has been seen in the PIV results of [24], perhaps reduce the aerodynamic drag experienced by the spray plumes in this region.

Although much about the spray formation and flow interaction can be learnt and described qualitatively through simple high-speed observation, unless these observations are related to useful engine performance metrics e.g. maximum in-cylinder pressure data and heat release rates, it is difficult to understand and justify their effects on their own. Further studies into the effects of spray-flow interactions and fuel type, as well as enginecoolant temperature, are carried out with simultaneous combustion imaging in order to be able to begin to quantify the relative effects of mixture preparation on combustion variability.

The discussion in the following sections forms the first part of this program of study. The work focused on developing the current experimental database and understanding sprays for part-load homogeneous DISI engine operation, typical of most city driving conditions and where real-world optimization is still a requirement in order to improve thermal efficiency, reduce fuel consumption and exhaust emissions. Therefore, the next sections will focus only on results acquired under WWMP conditions and observations related to WOT will not be discussed further. 


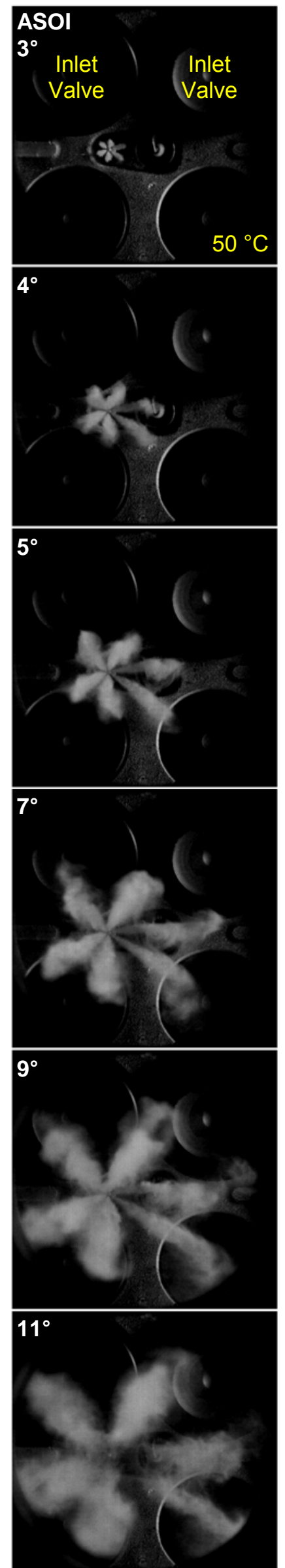

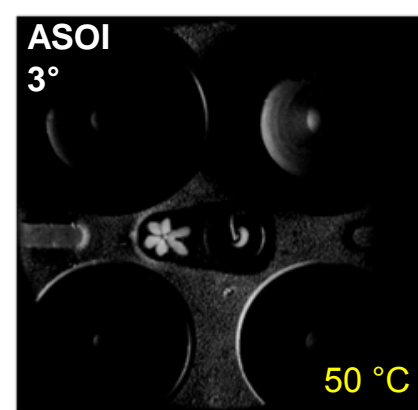
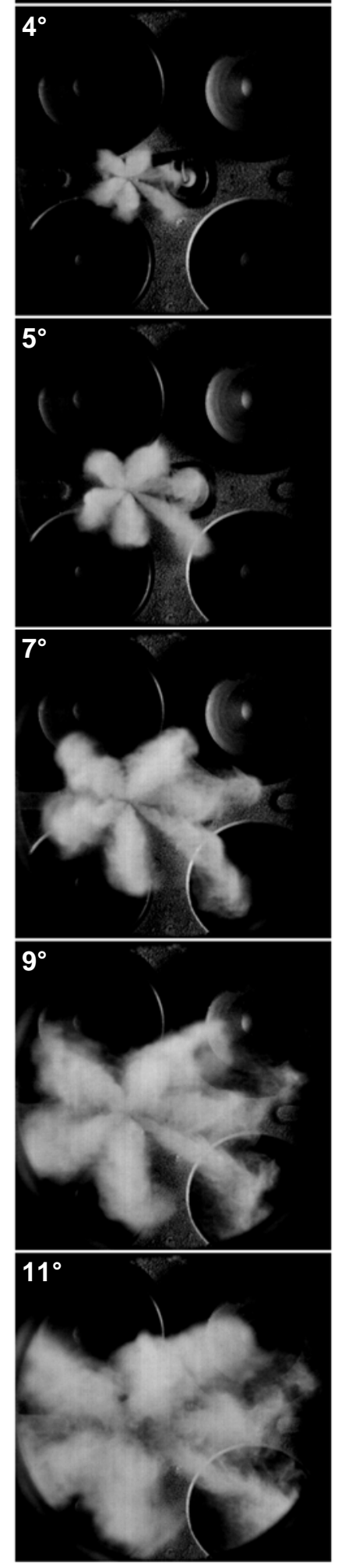
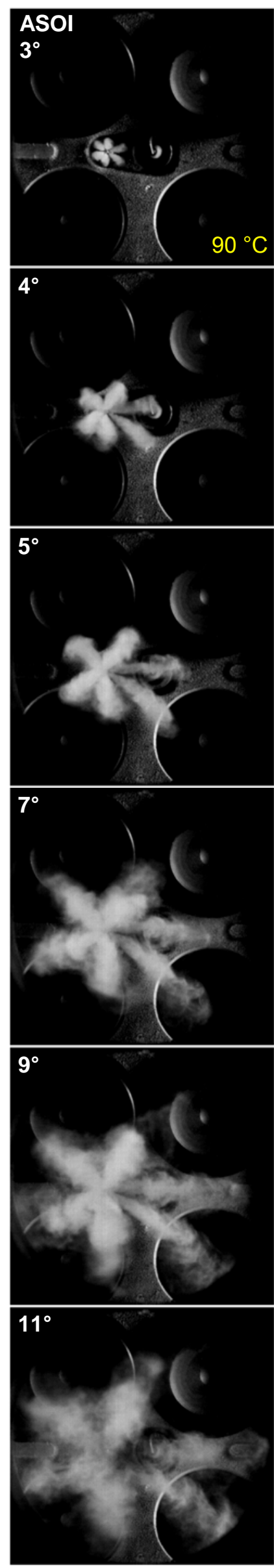
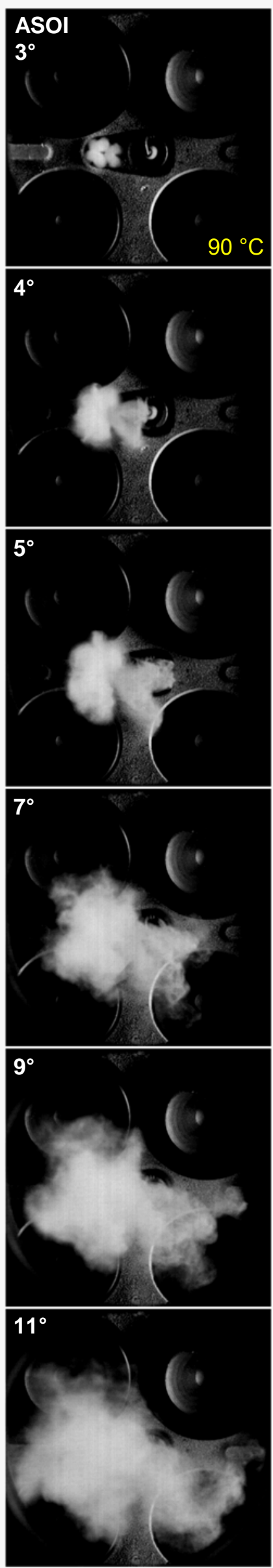

Figure 8. Spray Development for SOI $80^{\circ} \mathrm{CA}$ ATDC: Column 1 Iso-Octane $50^{\circ} \mathrm{C}$; Column 2 Gasoline $50^{\circ} \mathrm{C}$; Column 3 Iso-Octane $90^{\circ} \mathrm{C}$; Column 4 Gasoline $90^{\circ} \mathrm{C}$. 


\section{SPRAY ANALYSIS}

\section{EFFECT OF FUEL TYPE AND TEMPERATURE}

\section{SPRAY DEVELOPMENT - MOTORING}

Injection Strategy (Single): Under motoring conditions, with the spark disabled, 100 consecutive cycles of full spray development (at $1^{\circ} \mathrm{CA}$ resolution) were recorded. The injection pulse duration used was the same to that needed for a stoichiometric mixture under firing conditions with 0.5 bar intake pressure $(0.78 \mathrm{~ms})$.

The spray development for SOI $80^{\circ}$ CA ATDC was studied for iso-octane and gasoline at $50{ }^{\circ} \mathrm{C}$ and $90{ }^{\circ} \mathrm{C}$ engine-coolant temperature. At the crank-angle timing of $\mathrm{SOI}$, the intake flow valve jet is close to its peak velocity magnitude of 35-45 m/s, as reported in [25] using identical engine geometry. A typical cycle was selected to illustrate spray development for each of these motoring conditions, as shown in Figure 8.

Temperature Effects: The influence of engine-coolant temperature on the spray formation is clearly seen for both fuels tested. The spray plumes produced using isooctane appear thinner and better defined than for gasoline even at $50{ }^{\circ} \mathrm{C}$ coolant temperature, but the differences are particularly strong at $90{ }^{\circ} \mathrm{C}$ enginecoolant temperature. At this temperature the gasoline spray plumes are seen to partially collapse forming a cloud of liquid fuel and vapor in the region directly below the injector. The four main plumes produced from nozzles 2, 5 and 3 and 4 , participate in this collapse, whilst the other two produced from nozzles 1 and 6 collapsing to a lesser extent, possibly due to their different turning angles $[19,20]$. However, it was observed that there was a narrowing of the angle between plumes 1 and 6 (Figure 8). At $50{ }^{\circ} \mathrm{C}$ enginecoolant temperature, although the global spray formation appears more uniform for both fuels, the spray plumes for gasoline are noticeably wider. This is most likely as a result of the low boiling point factions in the gasoline evaporating and boiling off more rapidly, typical of multicomponent fuels like gasoline with wide distillation curves $[20,26]$. However, it can be seen that the plumes immediately after injection, in the near nozzle region, are already wider for gasoline, and therefore there must be other effects taking place very close to the nozzle or within the nozzle itself, such as cavitation, that result in the observed behavior (gasoline has a much higher vapor pressure than iso-octane) [19, 20, 27]. Instantaneous tumble plane shots for the same conditions (SOI $80^{\circ} \mathrm{CA}$ ATDC, 0.5 bar intake pressure) are shown for $8^{\circ} \mathrm{CA} A S O I$ in the backlit shadowgraphs of Figure 9 - for direct comparison with static rig tests carried out with the same injector and presented in [20] - and corresponding mean images acquired from the piston crown view in Figure 10. The spray behavior for both fuels is seen to be similar at $50{ }^{\circ} \mathrm{C}$ engine-coolant temperature in Figure 9 with comparable penetrations and cone angles between the two spray plumes imaged (i.e. plumes 3 and 4 which are in the foreground from this view). At engine-coolant temperature $90{ }^{\circ} \mathrm{C}$ the penetrations for iso-octane are slightly reduced but gasoline experiences a visually larger reduction than that at $50^{\circ} \mathrm{C}$.
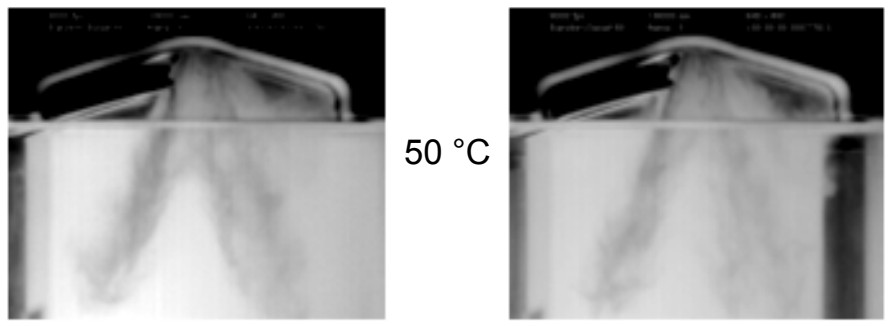

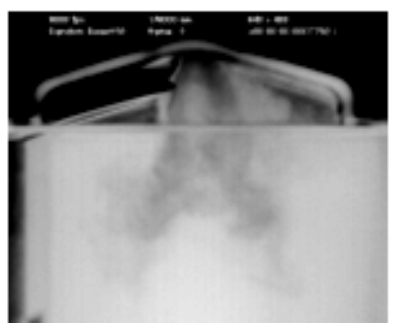

Gasoline

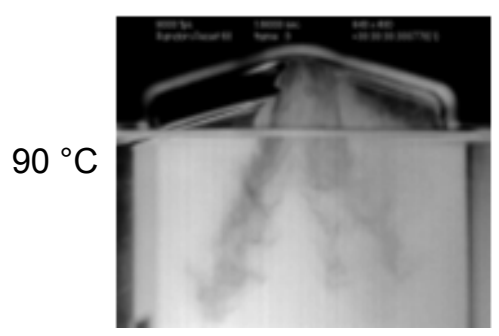

Iso-Octane
Figure 9. Spray Images on Tumble Plane (Backlit).
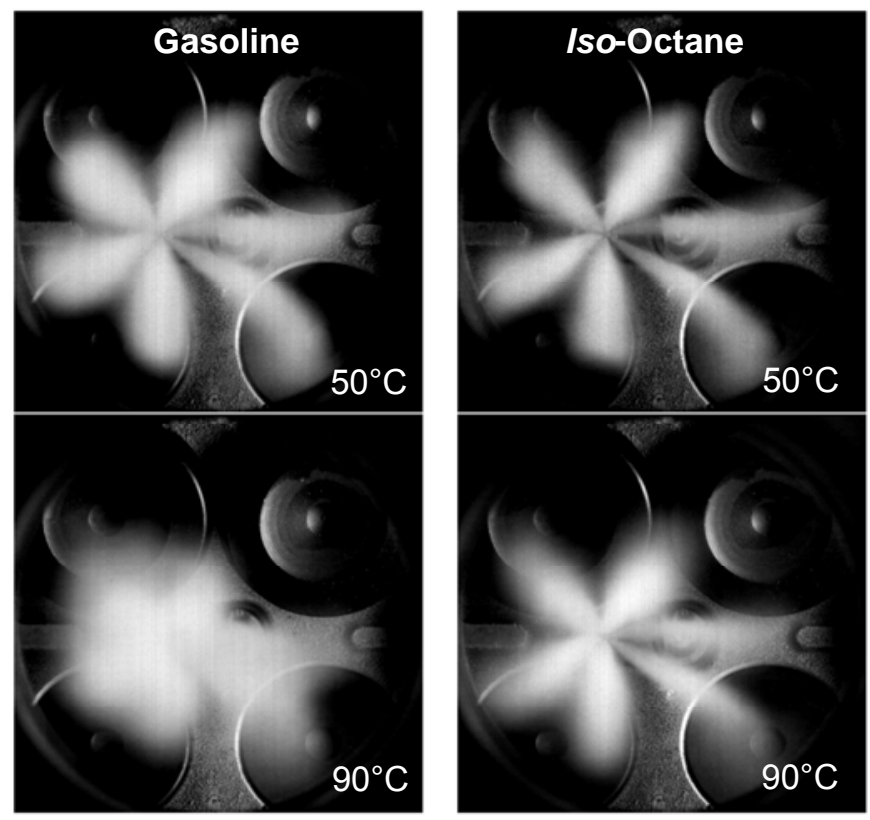

Figure 10. Mean Images Comparing Temperature and Fuel Effects on Spray formation, Motoring.

The observed effects are quantified in graphs of mean 'spray areas' calculated for the full injection event and post-injection timings, for 100 motoring cycles, shown in Figure 11. Spray areas are plotted normalized to the piston crown area such that 0.7 on the graph y-axis refers to $70 \%$ of the piston crown window area; the ratio of visible window area to the full cylinder bore area is $\sim 0.55$, with the window diameter corresponding to 0.73 of full bore diameter, i.e. $70 \%$ of the piston-crown 
window area corresponds to $\sim 40 \%$ of the engine full bore area. The mention of 'spray areas' from this point onwards will always refer to the areas defined as the 2-D projection of the sprays as seen through the piston crown.

The calculation of spray areas was done by binarizing the spray images. In order to achieve comparable results with different scattering intensities produced from the different test conditions, the images were processed to accentuate the liquid-core fuel areas, such that definition of the individual plumes was 'increased' in order to allow more accurate thresholding operation. This was done by applying a 'best-fit' function which sets the highest $3 \%$ intensity values of the image histogram to 255 (maximum for an 8-bit image) and the bottom 3\% to 0 (zero). Further processing with brightness-contrast balancing optimized the intensity histogram for each image batch thus reducing the sensitivity of the chosen threshold value. The number of pixels falling within this threshold were counted for each image frame and each of the 100 cycles to produce the mean curves in Figure 11. The first measurement of area is seen to occur at $3^{\circ}$ $\mathrm{CA}$ ASOI and this corresponds to the initial delay in fuel arrival at the injector tip which was found to be $100 \%$ repeatable for all conditions; this was further confirmed by the low coefficient of variations of area obtained for this crank-angle: $3.3 \%, 1.8 \%$, for gasoline at $50{ }^{\circ} \mathrm{C}, 90$ ${ }^{\circ} \mathrm{C}$ respectively and $4.7 \%, 3.1 \%$ for iso-octane $50{ }^{\circ} \mathrm{C}, 90$ ${ }^{\circ} \mathrm{C}$ respectively.

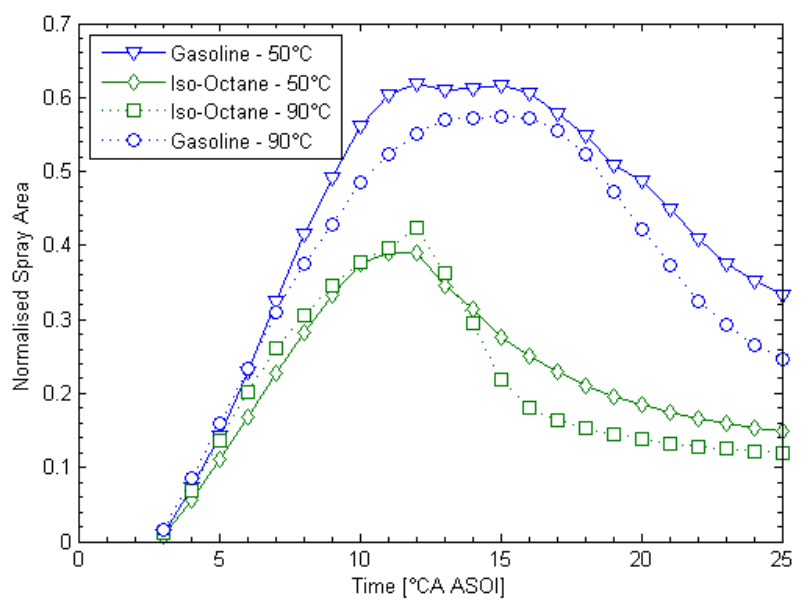

Figure 11. Mean Spray Areas for Motoring Conditions with SOI $80^{\circ} \mathrm{CA}$ ATDC.

The iso-octane spray is seen to have smaller absolute areas and lower rate of increase of areas for both temperatures considered, indicating thinner more compact plumes with similar levels of radial penetration relative to gasoline. For $90{ }^{\circ} \mathrm{C}$ engine-coolant temperature the rate of increase of area is seen to be marginally higher than that at $50{ }^{\circ} \mathrm{C}$ for iso-octane, but the opposite is true for gasoline. Extended observation of the injection events appear to show this effect to be the result of different levels of interactions from two mechanisms, namely air-spray interface vapor generation and leading edge evaporation. For iso-octane the higher liquid temperatures result in a slight widening of the spray plumes due to increased vapor generation at the spray interfaces (or due to different in-nozzle phenomena than those at the lower temperature) and a reduction in the liquid penetration due to increased evaporation at the leading edges. The combined effect is marginally larger measured spray areas and higher rate of growth in spray area, as the widening of spray plumes seems to compensate (in terms of area contribution) for the reduction in spray penetration. The difference in spray areas between $50{ }^{\circ} \mathrm{C}$ and $90{ }^{\circ} \mathrm{C}$ at end of injection $\left(11^{\circ} \mathrm{CA}\right.$ ASOI) was a $10-15 \%$ reduction for gasoline and only marginal iso-octane. After the end of injection $\left(11^{\circ}\right.$ CA ASOI, or $91^{\circ}$ CA ATDC), the spray area is seen to drop at a steeper gradient than for $50{ }^{\circ} \mathrm{C}$, as the spray evaporates quickly due to better mixing and the higher initial fuel temperature. After $\sim 15^{\circ} \mathrm{CA}$ ASOI, the area is seen to begin to tail off for iso-octane with a similar effect occurring - but to a lesser extent - for gasoline at $\sim 22^{\circ}$ $\mathrm{CA}$. This difference between the two fuels is probably because gasoline has slower overall rate of evaporation, owing to the heavier boiling fraction components in the blend that exist as liquid and scatter higher levels of light for longer than for iso-octane.

For gasoline, at the start of injection, the rate of increase of spray areas is higher than for iso-octane at both $50{ }^{\circ} \mathrm{C}$ and $90{ }^{\circ} \mathrm{C}$, highlighting the increased plume widths observed for these sprays (Figure 8). At $7^{\circ} \mathrm{CA}$ ASOI the spray area for gasoline becomes larger for the $50{ }^{\circ} \mathrm{C}$ condition relative to $90{ }^{\circ} \mathrm{C}$. The significant collapse of the spray plumes at $90{ }^{\circ} \mathrm{C}$, although producing a large uniform 'spray footprint' as observed from the piston crown view, also concentrates the majority of the spray in the centre of the window, thus resulting in a lower total measured spray area than for $50{ }^{\circ} \mathrm{C}$, where the six plumes are wide and spread out fairly symmetrically around the widow area. More significant however, is the replication of the trend seen for iso-octane, where the 90 ${ }^{\circ} \mathrm{C}$ spray evaporates more quickly after the end of injection, resulting in a faster drop in measured spray area as seen in Figure 11. Immediately after the end of injection, gasoline shows a fairly constant signal, indication of slower liquid evaporation, a result of continuous scattering by the heavy factions in the fuel. In the later post-injection stage however, the rate of decline of the gasoline spray areas appears to be similar to that of iso-octane for both engine-coolant temperatures and it may be hypothesized that this represents a stage in the evaporation process where the light fractions have already boiled off and the medium fractions are now the main participants in the majority of the evaporation process and in the subsequent reduction of the measured spray areas. This is plausible given that isooctane typically represents a mid-boiling point component in a multi-component gasoline fuel blend, and the similarities in the rate of change of spray areas therefore appear to be more than an interesting coincidence. 
For completeness, one note on the results is that, as can be seen from the images in Figures 8 and 10, the measured areas can only represent the true liquid spray in terms of absolute area up to $\sim 12^{\circ} \mathrm{CA}$ ASOI, since the high penetration from this point result in some 'clipping' of the spray due to the piston window size. Nonetheless, the results appear to show good representation of the observed effects as seen from raw video analysis.

\section{SPRAY DEVELOPMENT - FIRING}

In order to investigate the effects of combustion and the presence of hot residuals in the cylinder on the subsequent cycle spray formation, the engine was fired at $50{ }^{\circ} \mathrm{C}$ engine-coolant temperature with both fuels. Tests were not carried out with $90{ }^{\circ} \mathrm{C}$ engine-coolant temperature on this occasion to minimize risks associated with the operation of the dry piston rings.

Injection Strategy (Single): The fuel was injected initially with SOI $80^{\circ}$ CA ATDC. The injection duration necessary to achieve a stoichiometric mixture with 0.5 bar intake pressure at 1500 RPM was $0.78 \mathrm{~ms}$, as also used for the motoring tests described in the previous section.

It was observed that some 'thinning' of the plumes and reduced penetrations were evident particularly for isooctane under firing conditions, as shown in Figure 12, i.e. a general reduction in liquid spray mass. This is probably a result of increased heat transfer from higher chamber temperatures and the presence of hot combustion residuals, all increasing the evaporation rates at the spray-air interfaces. Higher injector tip temperatures are

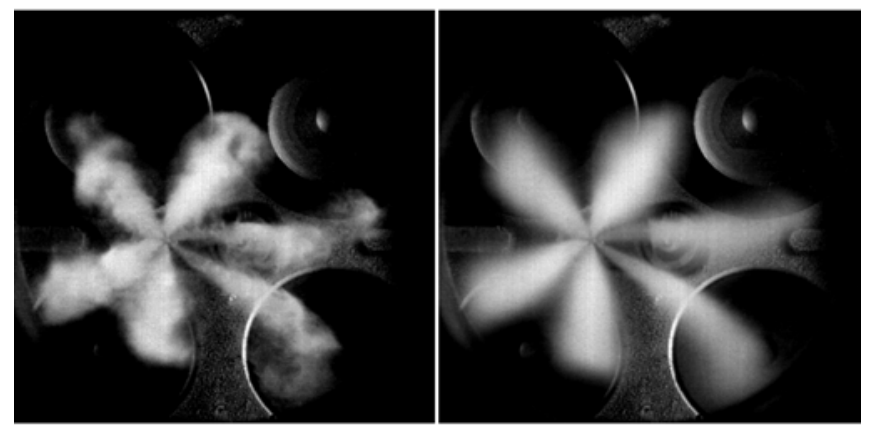

Motoring

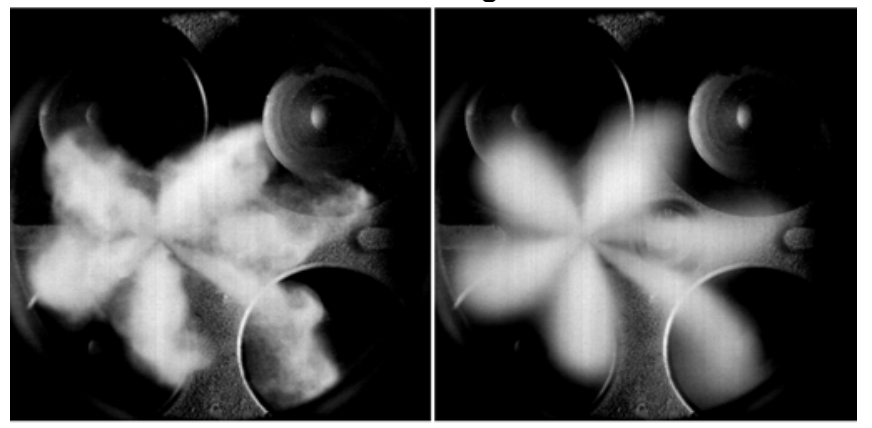

also expected to contribute to some extent to increased atomization efficiency as a result of higher levels of innozzle 'boiling'. The spray tips during injection also appear to be more severely deformed and distorted by the flow than in the pure motoring case, further supporting the hypothesis of increased leading edge vaporization; the reduced fuel mass at the leading edge of the spray and thus reduced spray-tip momentum likely results in the spray plumes becoming more susceptible to flow field effects, in particular relative to the strong valve jet which is present during the injection event for the injection timings used.

The 'firing' effects for gasoline are similar to those for iso-octane, however, for the multi-component fuel blend, the effect of low volatility components results in increased spray collapse as seen by the disappearing gaps between the individual spray plumes. In the mean image, not only is a clear reduction in penetration seen, but spray density is clearly reduced, with plumes appearing more transparent at the leading edges and spray-air boundaries, the two locations of expected increased evaporation. These effects are also revealed in the spray area analysis in Figure 13. Both gasoline and iso-octane exhibit a lower peak in spray area for the firing cycles. The difference in spray areas between motoring and firing conditions at end of injection $\left(11^{\circ} \mathrm{CA}\right.$ ASOI) was a reduction of $10-15 \%$ for iso-octane and $15-$ $20 \%$ for gasoline. For firing conditions, gasoline also shows a steep negative gradient of the area curve after the end of injection (11 $\left.{ }^{\circ} \mathrm{CA} \mathrm{ASOI}\right)$. For iso-octane the effects of a firing engine appear to be similar in terms of evaporation rates to those of increasing the coolant temperature from $50{ }^{\circ} \mathrm{C}$ to $90^{\circ} \mathrm{C}$.

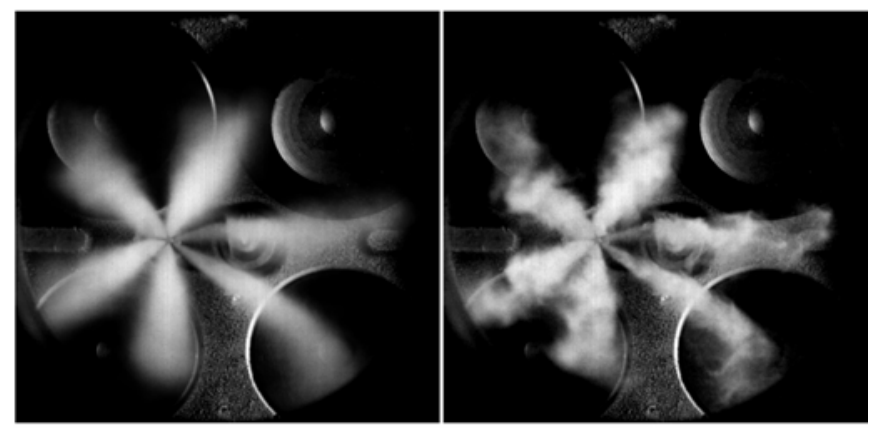

Firing

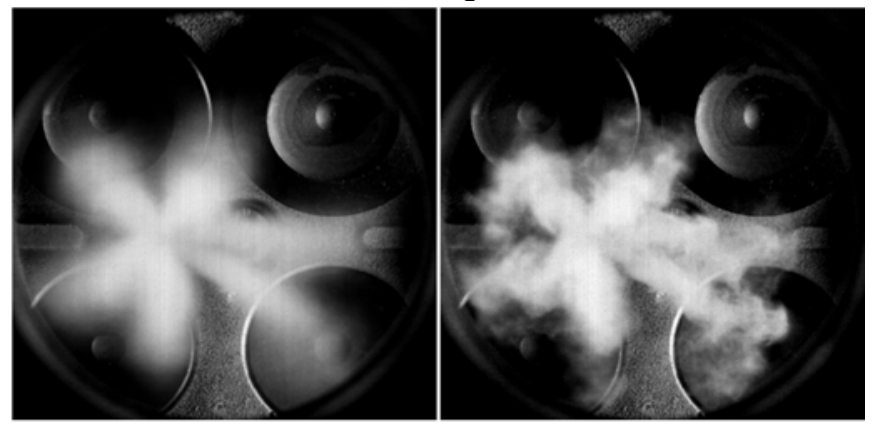

Figure 12. Sprays for Motoring and Firing Conditions: Iso-Octane (Top), Gasoline (Bottom); Columns 1 and 4 Single Shots, Columns 2 and 3 Mean Images; All Images at $8^{\circ} \mathrm{CA}$ ASOI with SOI $80^{\circ} \mathrm{CA}$ ATDC and $50^{\circ} \mathrm{C}$ EngineCoolant Temperature. 
Since spray areas are intrinsically linked to evaporation rates it is possible to stipulate that for gasoline the effect of firing on spray evaporation is indeed higher than that for iso-octane. This could be explained by the lower boiling point factions in the gasoline (in the range 50-70 $\left.{ }^{\circ} \mathrm{C}\right)$ participating in the evaporation process early on and resulting in proportionally more rapid evaporation than for iso-octane; this trend is indeed illustrated in Figure 13 below.

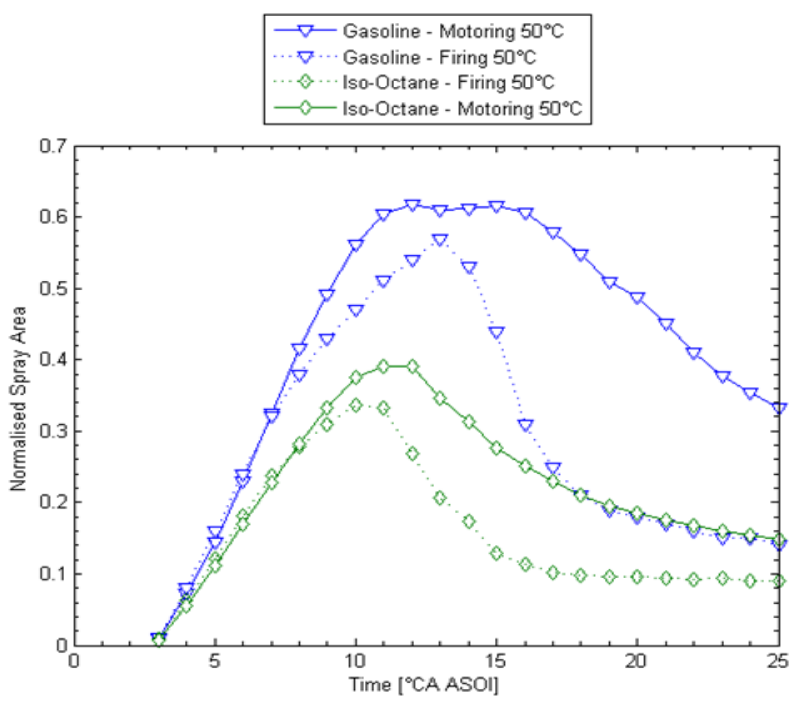

Figure 13. Mean Spray Areas for Motoring and Firing Conditions with SOI $80^{\circ} \mathrm{CA}$ ATDC.

\section{SPRAY VARIABILITY}

A typical sequence of spray images at $11^{\circ} \mathrm{CA}$ ASOI from 9 consecutive cycles for gasoline fuel with enginecoolant temperature $50{ }^{\circ} \mathrm{C}$ and $90{ }^{\circ} \mathrm{C}$ under motoring conditions are shown in Figure 14. The variation in measured spray areas from cycle to cycle can give an insight into the liquid spray pattern variations arising due to injector shot-to-shot variability superimposed with flowfield effects. Figure 15 and 16 show the spray area RMS for motoring and firing conditions. The maximum RMS is observed for iso-octane at $4^{\circ} \mathrm{CA}$ after the end of injection ( $25 \%$ at $\sim 15^{\circ} \mathrm{CA}$ ASOI), for the low enginecoolant temperature. Increasing the coolant temperature is seen to bring the peak level of RMS for iso-octane considerably down (by $\sim 40 \%$ ) and earlier in the cycle (by $\sim 2^{\circ} \mathrm{CA}$ ). The much lower peak in RMS at the higher engine-coolant temperature shows a more 'consistent' spray formation and evaporation for iso-octane at this temperature on a cycle-by-cycle basis. Similar effects are observed for the firing condition with iso-octane, consistently exhibiting larger RMS in spray area than gasoline does. However, the peak in RMS is lower than that for motoring conditions (by $\sim 20 \%$ ) which strengthens the argument about more consistent spray formation and evaporation at higher temperatures. Gasoline exhibits a peak in the RMS of spray areas quite late after the end of injection than iso-octane does $\left(20^{\circ} \mathrm{CA} \mathrm{ASOI}\right)$, having similar behavior for both engine-coolant temperatures of
$50{ }^{\circ} \mathrm{C}$ and $90{ }^{\circ} \mathrm{C}$. Under firing conditions, the peak in RMS also occurs earlier (by $\sim 3^{\circ} \mathrm{CA}$ ), but the magnitude does not seem to be highly affected by the higher incylinder temperatures.
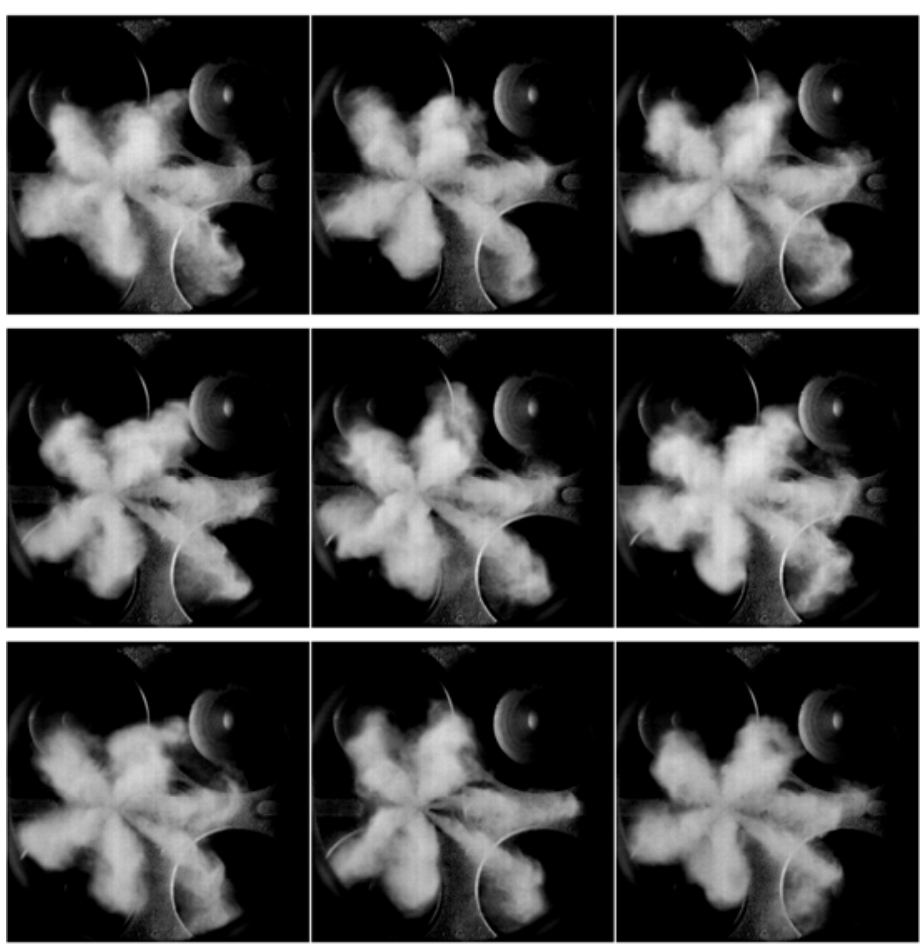

$50{ }^{\circ} \mathrm{C}$
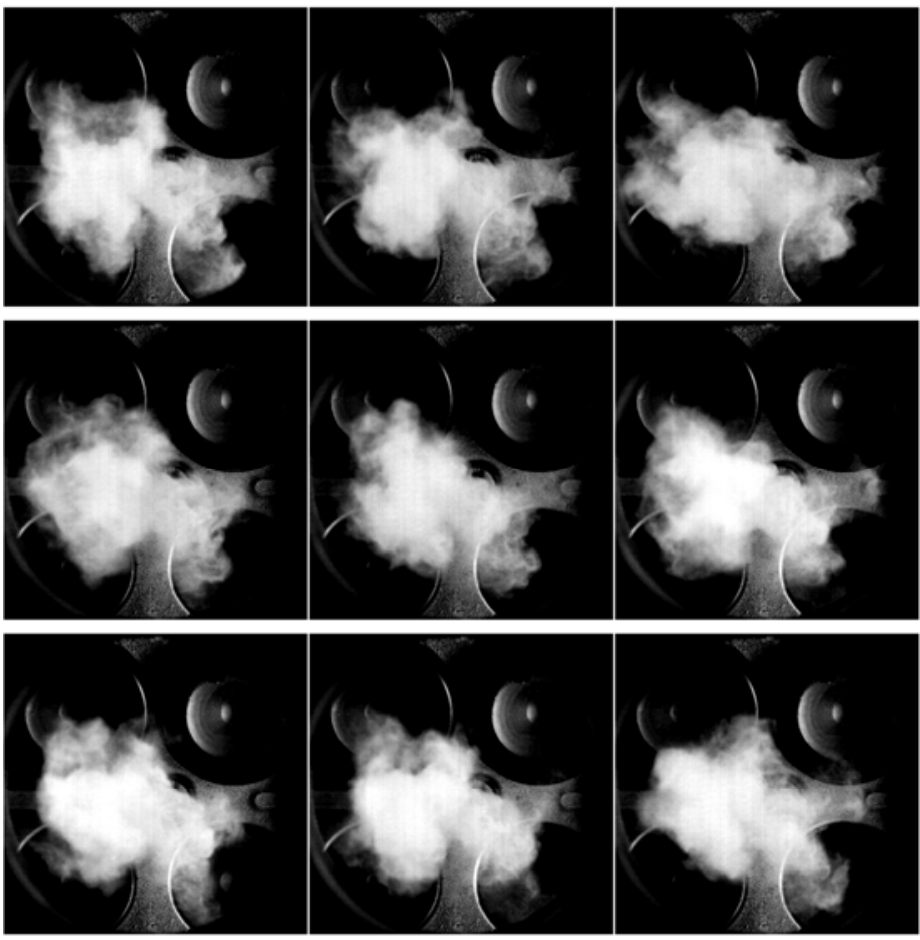

$90{ }^{\circ} \mathrm{C}$

Figure 14. Variability of Gasoline Sprays at $8^{\circ} \mathrm{CA}$ ASOI (88 ${ }^{\circ}$ CA ATDC) with Different Engine-Coolant Temperatures. 


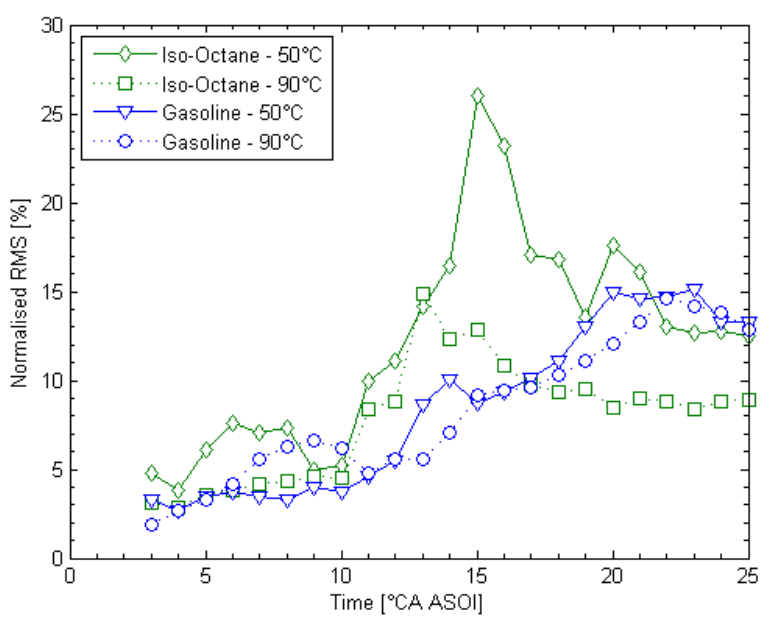

Figure 15. RMS of Spray Areas for Motoring Conditions with SOI $80^{\circ} \mathrm{CA}$ ATDC.

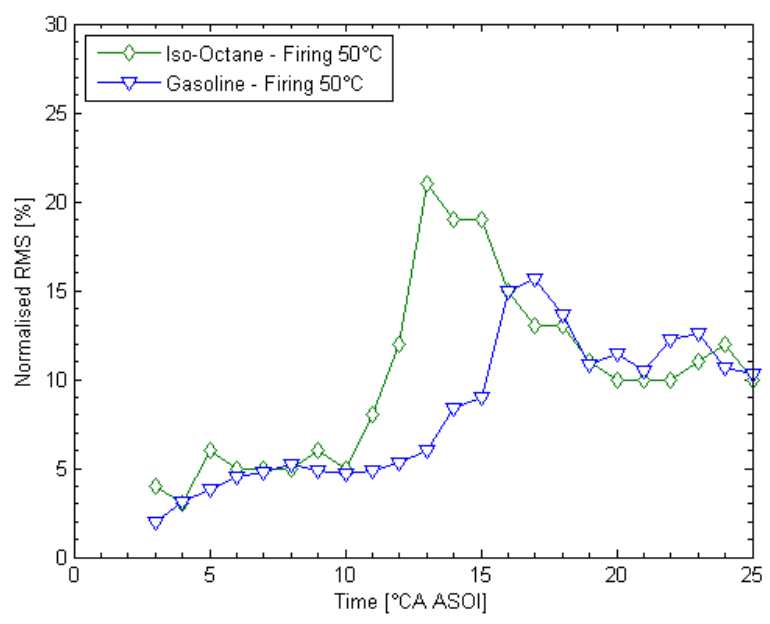

Figure 16. RMS of Spray Areas for Firing Conditions with SOI $80^{\circ} \mathrm{CA}$ ATDC.

Injection Strategy (Multiple): A multiple injection strategy was also investigated as a means to control mixture formation and combustion, and also as an attempt to reduce the likelihood of direct liquid impingement on incylinder surfaces. Images from a representative cycle showing the triple-injection event are presented in Figure 17. The triple-injection timings and durations were seen to be consistent on a cycle-by-cycle, although the second and third injection always seemed to be associated with 'more' fuel at the injector tip in the frame where fuel was typically first seen. The exact reasons for this are not yet fully understood since the injector operation was very repeatable for single-injection strategies as characterized in [19]. Ongoing tests are trying to determine whether these are injector-hardware or fluid dynamic effects. However, since the effect was always consistent when using triple injections, it did not affect the objectives of the current test methodology.
It was observed that use of a multiple-injection strategy can indeed reduce direct liquid fuel impingement on incylinder surfaces and potential associated effects with exhaust emissions It was also generally observed that the shorter split injections produced more rapid evaporation and mixing than the single injections and this was verified by comparing mean and RMS spray images for single and multiple-injection strategies during the injection process, as well as after the end of injection. Such findings are not uncommon and indeed other studies of split injections for DISI engines have also reported improved air entrainment, mixing and evaporation [28]. Spray-gas momentum transfer is considered critical for defining spray structure and driving the efficiency of mixture preparation process. Previous work with single-injection strategies has pointed out that one of the characteristics with multi-hole injectors is that they produce a very robust spray pattern aligned in straight lines, as also highlighted in the present study, and consisting of individual vapor branches rather than forming a complex cloud structure [29, 30]. The former is true under high gas pressures, where spray collapse does not normally occur, and thus is mainly relevant for stratified operation with late injection. However, in the present study, the effect of low in-cylinder pressure during injection might result in these vapor branches becoming less stable and more prone to flow field induced interactions for single injection events. The use of multiple injections attempts to reduce the effect of strong direct spray-flow interactions during injection and artificially control the mixing process by enhancing physical mechanisms, such as spray-induced flow recirculation under the nozzle typically seen for pure hollow cone injectors [29], improving mixing through repeated forced spray-gas momentum transfer and maximizing the effect of wakes behind fuel droplets to increase the turbulence intensity and fuel vapor diffusion [31].

\section{COMBUSTION ANALYSIS}

\section{EFFECT OF FUEL AND INJECTION STRATEGY}

\section{FLAME GROWTH IMAGING}

In order to investigate some of the spray effects with respect to subsequent combustion in each cycle for different fuels and injection strategies, a study was carried out to capture images of both the injection event and combustion in the same cycle for a batch of consecutive cycles, as well as in-cylinder pressure data. Time-resolved flame growth is shown in Figure 18 for several crank angle degrees After Ignition Timing (AIT). The flame images are shown with the same contrast such that they reflect true relative levels of natural flame luminosity. Gasoline single injection showed the highest flame luminosity, followed by iso-octane flames and then triple-injection gasoline flames, although iso-octane flames were sometimes initially very faint, even fainter than those of triple-injection gasoline. 

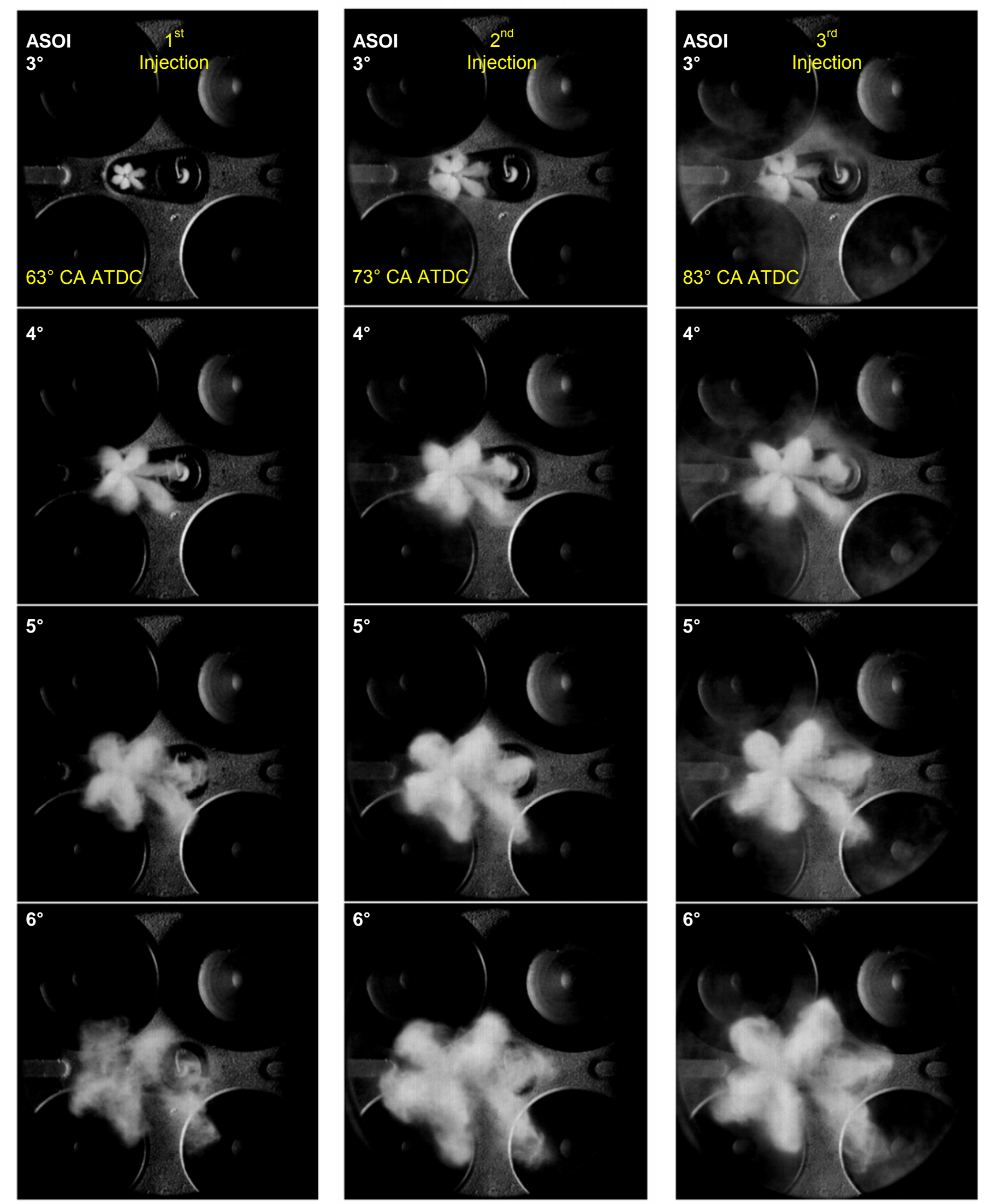

Figure 17. Spray Development for Triple Injection with SOI $60^{\circ}, 70^{\circ}, 80^{\circ} \mathrm{CA}$ ATDC, Gasoline $\left(50^{\circ} \mathrm{C}\right)$. 


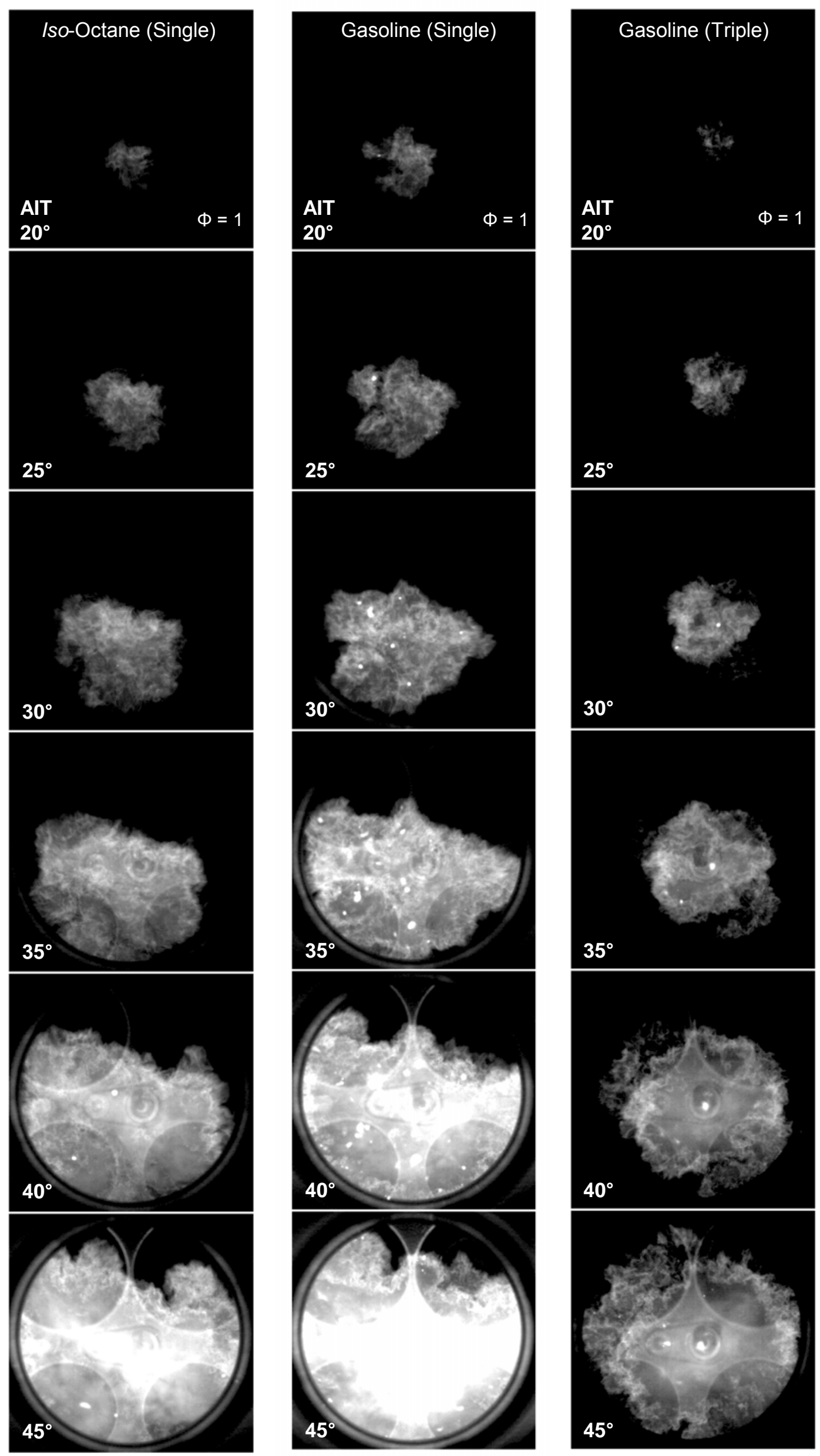

Figure 18. Fame Growth for Single-Injection and Triple-Injection Strategies. 
Flame growth is noticeably faster on average with gasoline although iso-octane flames grow in similar shapes and directions to those of gasoline. The same cannot be said using triple-injection gasoline, where not only is combustion noticeably slower, but the flame in this case appears to grow much more 'spherically' with only small displacement from the spark electrode, in comparison to the significant flame growth towards the exhaust side for gasoline and iso-octane single-injection strategies. A number of mechanisms may responsible for this behavior, from varying concentrations of air-fuel ratio distribution around the spark plug, increased heattransfer, flow and temperature field effects, which cannot be separately identified at this stage. However the effect of multiple injections on combustion seems clear and the difficulties lie in understanding the hierarchy in which such mechanisms act to produce such behaviour. It was also noticed, that single-injection flames appeared to retain their early shape features throughout combustion; early features of combustion such as a flame 'branch' with troughs on either side remained intact for the initial growth period $10-45^{\circ}$ CA AIT, whereas triple-injection flames seemed to grow by a less defined continuous flame front and with lower-intensity islands of burning mixture appearing ahead of the flame, i.e. with more 'fragmentation' of the flame front.

The low luminosity flames for triple-injection gasoline may be associated with other features of the flow field and mixture formation that are hidden using only natural light flame imaging and liquid spray imaging. However in any case such flames may indicate lower levels of soot production which, if true, have the potential to reduce one of the major emissions obstacles currently associated with DISI engines. In particular, although single-injection gasoline flames exhibited consistently bright spots that could indicate the presence of rich fuel areas and droplets burning, triple-injection gasoline exhibited very few bright spots on a cycle-by-cycle basis. Such effects would be compatible with earlier observations about triple injection leading to different spray delivery and mixture formation. Lower luminosity combustion and spherical flame growth resonate more with traditional stoichiometric PFI charge preparation combustion systems than DISI systems and it is possible that split injections are achieving similar levels of charge homogeneity typical of PFI engines under steady-state conditions [2-5].

\section{IN-CYLINDER PRESSURE DATA}

The mean relationships for in-cylinder pressure history and mass fraction burned are shown in Figures 19 and 20, respectively. Single-injection gasoline showed the highest peak pressure $P_{\max }$, followed by iso-octane and then triple injection gasoline. The same trend was seen for the phasing of MFB, with single-injection gasoline exhibiting the fastest combustion dictated by a faster initial flame kernel growth in the $0-30^{\circ}$ CA AIT range (i.e. $325-355^{\circ}$ CA ATDC), corresponding typically to the duration of $0-10 \%$ MFB $\left(\theta_{\times b 10 \%}\right)$. The spread of $P_{\max }$ was also seen to be lower for single-injection gasoline which resulted in lower values of coefficient of variation of $P_{\max }$ and IMEP. Iso-octane showed an increased level of scatter in these parameters and triple injection showed the greatest degree of scatter in the magnitude and phasing of $P_{\max }$, although the resulting mean $P_{\max }$ was similar to that of single-injection iso-octane. Typical values of coefficient of variation of $\mathrm{P}_{\max }$ were $8 \%$ for isooctane single injection, $6 \%$ for gasoline single injection and $12 \%$ for gasoline triple injection. Using triple injection, there was also a number of partial-burn cycles $(\sim 5 \%$ of the cycles) including a couple of cycles that would be termed 'misfires', even though the air-fuel ratio sensor consistently displayed $\Phi=1$. The time elapsed before registering a flame kernel on the images was seen to vary between $5-15^{\circ} \mathrm{CA}$ AIT, although for singleinjection gasoline a flame kernel was always seen before $10^{\circ} \mathrm{CA}$ AIT. For iso-octane single injection and gasoline triple injection though, it was only after $12-15^{\circ}$ CA AIT that all the cycles registered a measurable flame kernel. In terms of variation in $\theta_{\mathrm{xb} 10 \%}$, gasoline single injection showed the most robust performance with all cycles falling within a $6^{\circ} \mathrm{CA}$ range; iso-octane was found to lie in between triple and single-injection gasoline cases.

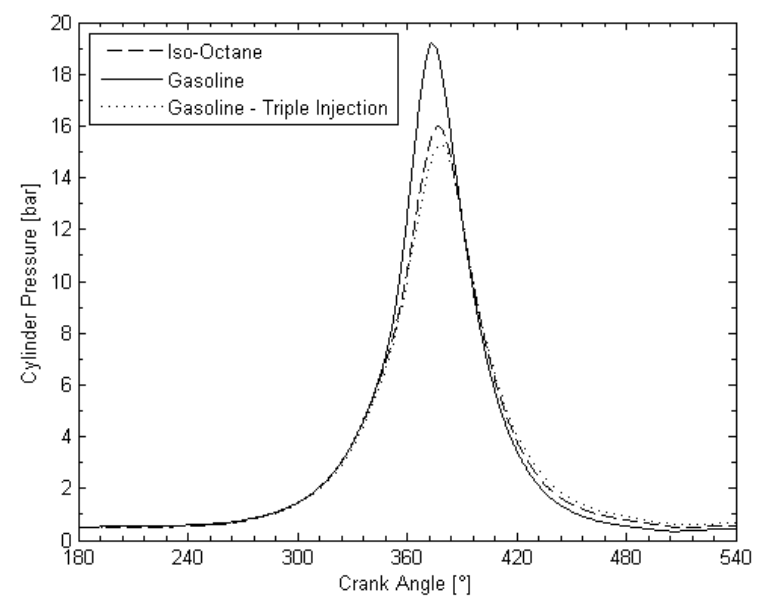

Figure 19. Mean In-Cylinder Pressure.

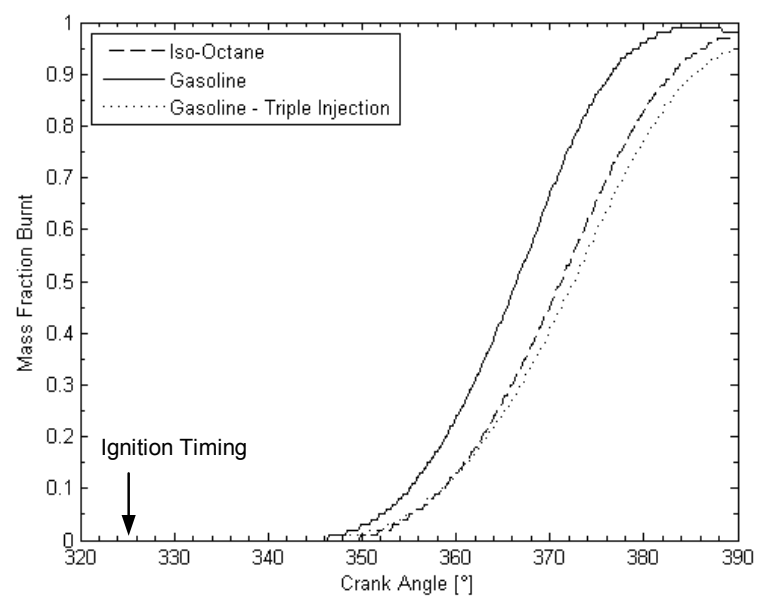

Figure 20. Mean Mass Fraction Burned. 

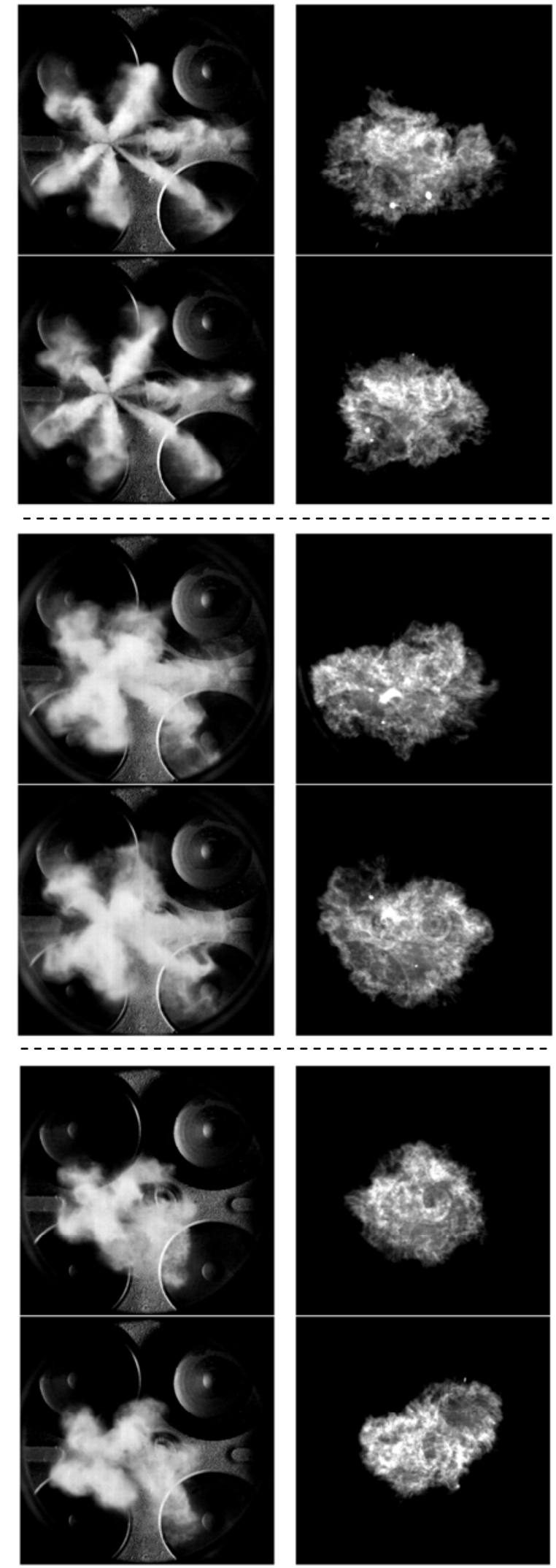

Figure 21. Images of Same-Cycle Sprays and Flames for 'Good' Cycles: Iso-Octane Single Injection (Top), Gasoline Single Injection (Centre) and Gasoline Triple Injection (Bottom).
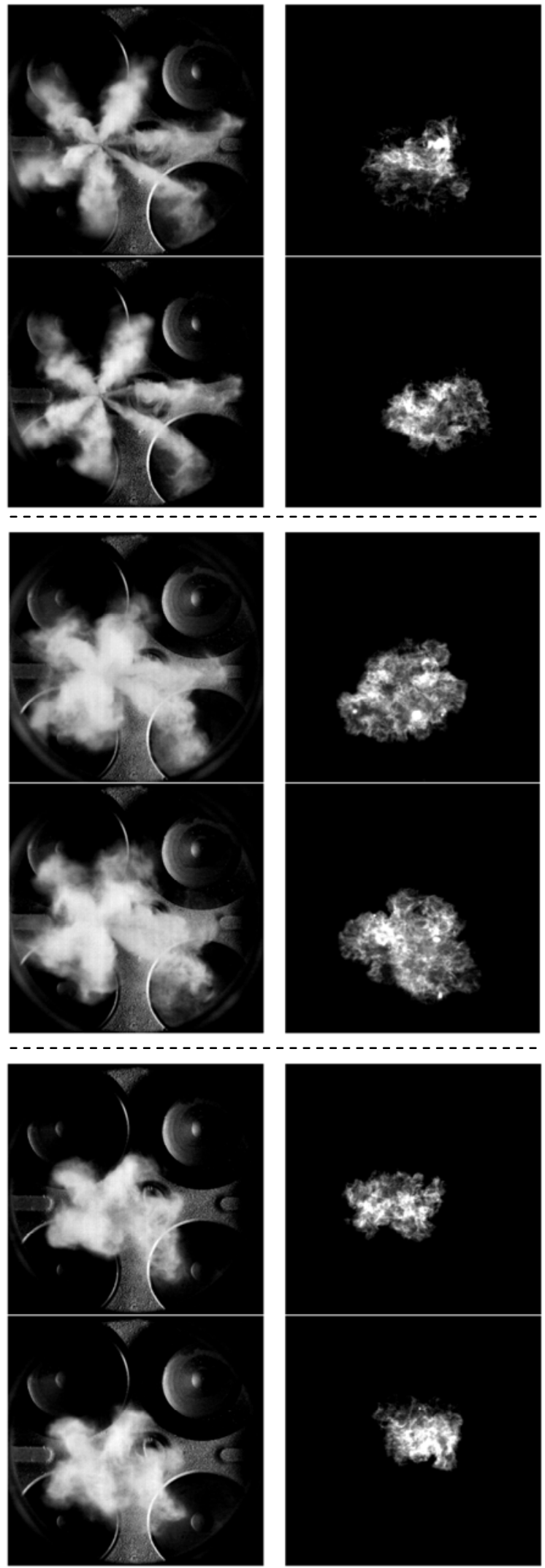

Figure 22. Images of Same-Cycle Sprays and Flames for 'Bad' Cycles: Iso-Octane Single Injection (Top), Gasoline Single Injection (Centre) and Gasoline Triple Injection (Bottom). 
It needs to be reminded here that these results indicate differences between the fuels and injection strategies for fixed ignition timing ( $325^{\circ} \mathrm{CA}$ ATDC). This approach was to allow comparisons to be carried out at the same reference in-cylinder pressure, temperature and flowfield conditions at ignition timing, mainly for the purpose of optical study. When individual cycles with similar timings of $50 \%$ MFB were compared to each other for the three test cases, i.e. when slow single-injection gasoline cycles were compared to fast triple-injection cycles and single-injection iso-octane, they showed similar $P_{\max }, \theta_{P_{\max }}$ and flame growth rates. This indicated that with optimization of the ignition timing, triple-injection gasoline could achieve similar levels of 'performance' to the single-injection strategy. An investigation is currently being performed to address this issue and results will be presented in a forthcoming publication.

'Good' and 'Bad' cycles were identified in terms of their angle of $10 \%$ MFB $\left(\theta_{\mathrm{xb} 10 \%}\right)$ and the two 'best and worst' spray and flame pairs from the same cycle are shown for the single-injection gasoline, single-injection iso-octane and triple-injection gasoline in Figures 21 and 22. The triple-injection sprays shown are for $6^{\circ} \mathrm{CA}$ ASOI for the third injection ( $86^{\circ} \mathrm{CA}$ ATDC), in comparison to $8^{\circ} \mathrm{CA}$ ASOI for the single-injection strategy, because injection had finished by this time and little could be seen of a formed spray pattern. The single-injection sprays are shown at $8^{\circ} \mathrm{CA}$ ASOI $\left(88^{\circ} \mathrm{CA}\right.$ ATDC) because they are more likely to show differences between 'Good' and 'Bad' cycles as a result of greater flow interactions at this point, compared to the more robust spray shape seen at $6^{\circ} \mathrm{CA}$ ASOI which would allow direct comparison between single and triple injections. All the flames are shown for $30^{\circ}$ CA AIT. There are small differences in the sprays for 'Good' and 'Bad' cycles but when calculated spray areas were plotted against $\theta_{\mathrm{xb} 10 \%}$, no correlation was observed for any of the conditions. The flames on the other hand showed clear differences between 'Good' and 'Bad' cycles and a strong correlation was observed between flame size and $\theta_{\mathrm{xb} 10 \%}$ from as early as $15^{\circ} \mathrm{CA}$ AIT. The same trends seen in Figures 19 and 20 are observed here too, with gasoline single-injection strategy producing the largest flames for 'Good' cycles, followed by single-injection iso-octane and triple-injection gasoline flames.

The lack of correlation between spray areas and subsequent heat release rates appears to suggest that combustion is not as dependent on the actual spray formation on a cycle-by-cycle basis with this injector and for 'fixed' injection strategy over a series of cycles, as may previously have been thought. More likely is that the injector produces a repeatable enough and robust spray, such that mixture transport due to post-injection incylinder flow becomes more dominant in terms of defining the final field of fuel concentration. However, changing the injection strategy from single to triple showed big differences in the features of flame growth which may suggest that there is further scope for optimization using multiple-injection strategies. This could perhaps include even different numbers of multiple injections in each cycle using some form of real-time feedback control from the engine.

\section{FLAME GROWTH AND MOTION}

Flame Growth: Flame areas were obtained by binarizing each flame image. Since no image intensifier was used in this set-up, flame intensities during the initial phase of combustion $\left(0-15^{\circ} \mathrm{CA}\right.$ AIT) were quite low, and the threshold value had to be lowered to levels of $\sim 5 / 255$. Although maintaining this value through the flame growth period results in a small degree of over-estimation of projected flame areas in the period from $35^{\circ}$ CA AIT onwards, it was decided that this was a more robust methodology for relative comparisons, rather than processing the flame images with changing threshold values to reflect changes in the mean flame intensity. In fact, the latter was attempted and was found to be difficult to implement reliably in an automated manner, due to random localized areas of image saturation potentially due to droplet combustion - which elevated the automatically identified threshold value to levels above the 'true' mean, and did not reproduce the flame outline accurately.

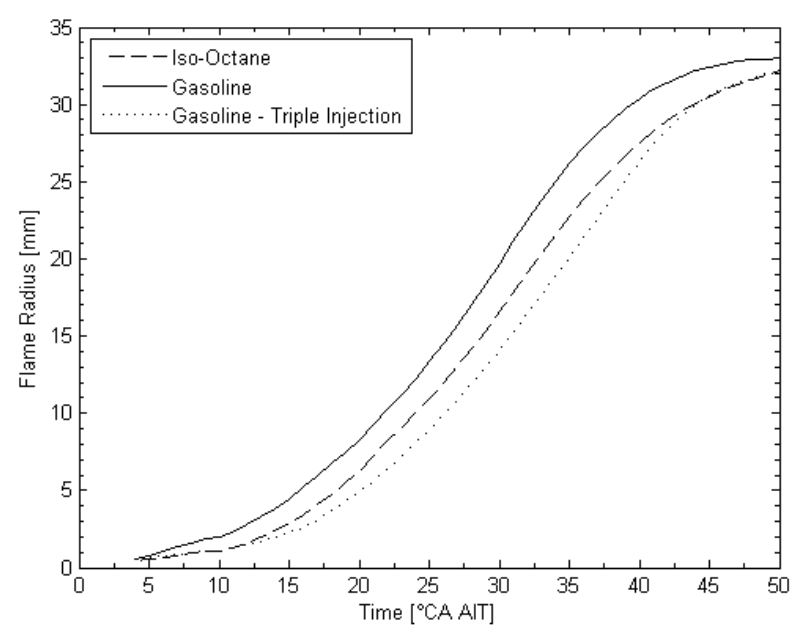

Figure 23. Flame Radius.

The growth in flame size is plotted in terms of an equivalent flame radius in Figure 23 , calculated as the mean from the flame areas of all cycles. It should be pointed out that the maximum flame radius shown corresponds to the edge of the optical piston crown which was $65 \mathrm{~mm}$ in diameter. In order to provide a link between Figure 23 and the MFB traces shown earlier in Figure 20, the flame radius was used to estimate the burned volume of the gas on the basis of an equivalent sphere. For a flame radius of $15 \mathrm{~mm}$, which corresponds on average to $25-30^{\circ} \mathrm{CA}$ AIT, the mass fraction burned was calculated from the volume fraction to be of the order $5-10 \%$ for a ratio of unburned-gas to burned-gas densities of the order 4. This is in agreement with Figure 20 and it highlights that flame radii in Figure 23 demonstrate phenomena very early in the cycle that the 
in-cylinder pressure analysis cannot capture reliably on a cycle-by-cycle basis. As can be seen from the flame images in Figure 18, typically flames are 'clipped' by the boundaries of the optical piston crown from $\sim 30^{\circ} \mathrm{CA}$ AIT onwards, mainly for single-injection strategy with both gasoline and iso-octane fuels. The following discussion should therefore bear in mind that a degree of masking will be introduced in the quantification of the flames which get convected towards the cylinder walls by the tumble motion, relative to those that grow centrally around the spark plug.

The flame radius in Figure 23 is seen to agree with the previous results of mass fraction burned, highlighting the faster initial flame kernel growth for single-injection gasoline relative to iso-octane and triple-injection gasoline, from very early in the cycle. In the phase $0-10^{\circ}$ CA AIT (corresponding to values below 1\% MFB), the rate of flame growth is initially higher than that just after $10^{\circ} \mathrm{CA}$ AIT for all conditions. Investigation of the combustion movies showed that this phase corresponded on average to the duration of spark discharge, producing high-luminosity early flame kernels and therefore some 'assistance' in initial flame growth. Once this is finished (i.e. after $10-15^{\circ}$ CA AIT), the flames slow down temporarily before further growth and expansion into the unburned gas regions.

The flame growth speed is shown specifically in Figure 24 . This increases steadily from a value close to that of laminar burning in the early stages, to about one order of magnitude greater at $25-35^{\circ}$ CA AIT. Single-injection gasoline shows higher initial growth speed and peak value than iso-octane and triple-injection gasoline. During early combustion $\left(0-30^{\circ} \mathrm{CA}\right.$ AIT) in particular, the flames exhibit periods of speeding up and slowing down at similar points in time with corresponding periods of 'constant' speed flame growth in between. It seems that the trend is more accentuated with gasoline, which would point towards this being a fuel effect rather than a flowfield effect. However, it is likely that this is a combination of both.

Triple injection reveals a slower flame growth in general, with a peak of flame growth speed later in time. However, the trends largely disappear if flame speed is plotted with respect to flame size in Figure 25. The reduction in flame growth speed for iso-octane after 20 $\mathrm{mm}$ flame radius relative to triple-injection gasoline is a result of the iso-octane's growth towards the exhaust side up until this point; having reached the walls on the exhaust side, the iso-octane flame continues to propagate across the combustion chamber to the intake side at a reduced speed. At $20 \mathrm{~mm}$ flame radius, or $32^{\circ}$ CA AIT, some 'clipping' of the flame area (as dictated by the limitations in optical access) is already occurring for iso-octane, whereas for triple-injection gasoline flames, the full effect of flame growth is actually being measured 'properly' throughout the combustion duration due to its centralized flame growth until much later $\left(\sim 40^{\circ} \mathrm{CA}\right.$ AIT $)$. The crossing of the two growth speed lines in time in
Figure 24 is analogous to the crossing of the flame growth curves in Figure 23, as triple-injection gasoline burns faster and for longer than single-injection isooctane. The slower early flame growth period for triple injection however, results in a sub-optimal phasing of $P_{\max }$ and $\theta_{\mathrm{Xb5} 5 \%}$, which results in overall marginally lower $P_{\max }$ in Figure 19.

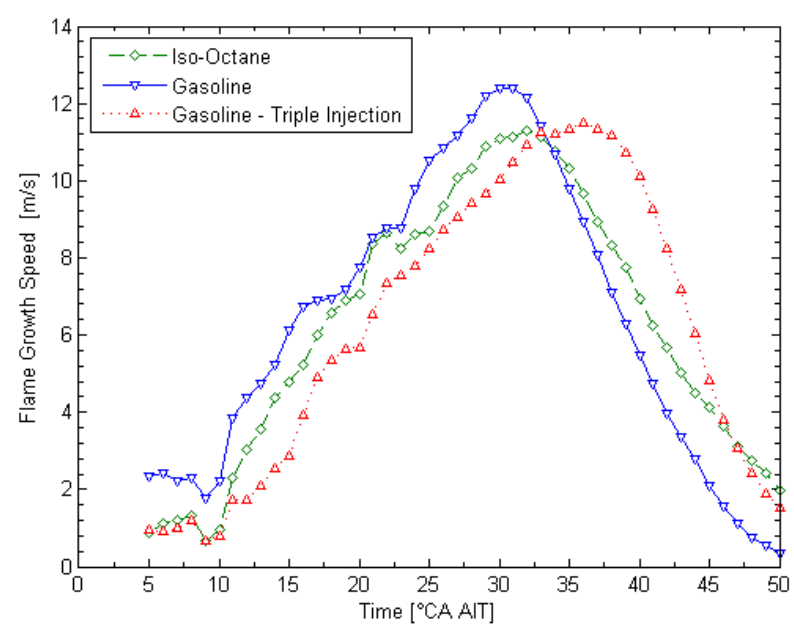

Figure 24. Flame Growth Speed.

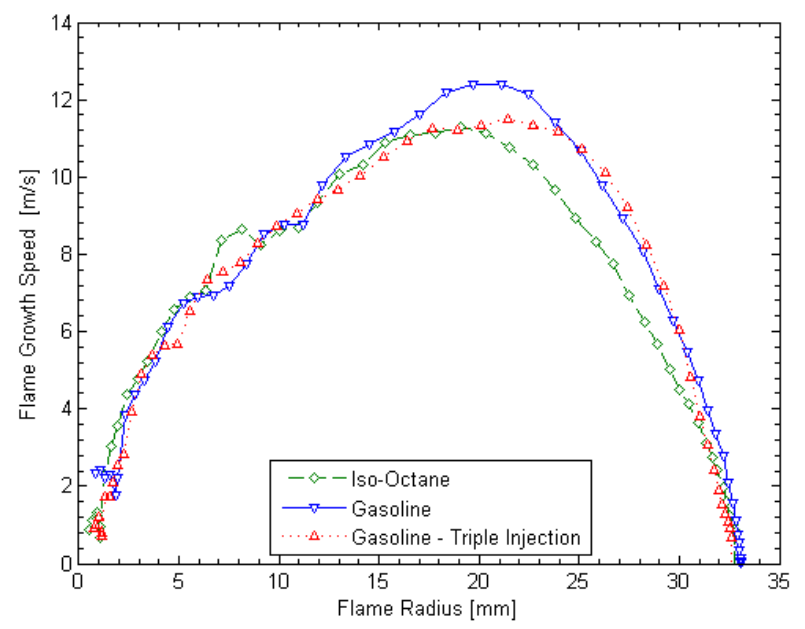

Figure 25. Flame Growth Speed versus Flame Radius.

Flame Centroid Motion: Early kernel growth is generally believed to be affected by two main features of the flowfield: large-scale convection by 'bulk' motion and smallscale turbulence. In practice, and from the experimentalist's point of view, it is very difficult to decouple these effects reliably and consistently on a cycle-by-cycle basis; in fact the flame 'sees' increasing number of sizes and frequencies of turbulent length scales as it grows. The flame centroid displacement can be seen from pictures as an indication of the movement of the flame kernel due to flows around it during its growth. The centroids of flame areas were calculated using a specially developed automated processing routine and the extracted flame centroid co-ordinates were plotted to show how the flame is displaced from the 


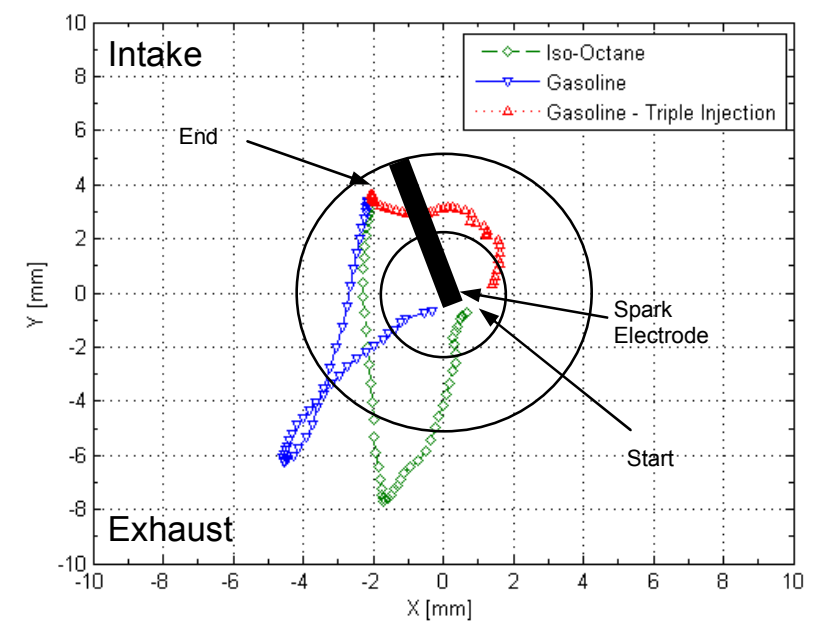

Figure 26. Flame Centroid Locations (4-60 ${ }^{\circ} \mathrm{CA}$ AIT).

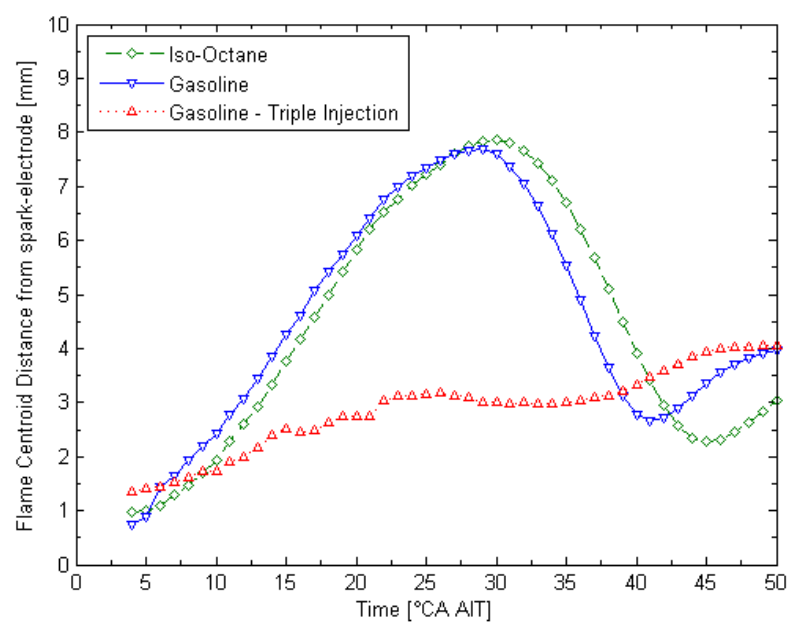

Figure 27. Flame Centroid Distance from Spark Plug.

spark-plug electrode in Figure 26 from as early as $4^{\circ} \mathrm{CA}$ AIT to $60^{\circ}$ CA AIT. The $(0,0)$ point in Figure 26 represents the spark-plug electrode tip as superimposed on the graph. It is interesting to note that the different fuels and strategies are associated with clearly different flame-centroid movements. The end points are the same for all three test cases and directly equivalent to the centre of the optical piston crown as the flame 'aligns' itself with the centre of the bore during completion of the combustion process.

The centroid paths in Figure 26 quantify the initial movement of the gasoline and iso-octane single-injection flames towards the exhaust side of the engine and the subsequent change of direction towards the intake side. For triple-injection gasoline the flames do not appear to move nearly as much and the centroid path is much shorter. In order to add a temporal dimension to the trends presented in Figure 26, Figure 27 shows the change in 'centroid distance' from the spark plug, i.e. from the $(0,0)$ point, with time. Broadly speaking, this figure shows that the single-injection flames travel relatively uniformly away from the spark plug in the period from $0-30^{\circ} \mathrm{CA} \mathrm{AIT}$, corresponding to the mean duration of $\theta_{\mathrm{xb} 10 \%}$, although not necessarily in the same directions. The first inflection point corresponds to the change in direction of flame growth from the exhaust side towards the intake side and therefore back towards the spark plug. The second inflection results as the centroids move past the spark electrode towards their final co-ordinate position, as shown in Figure 26.

For triple-injection flame, the larger initial centroid distance from the spark plug and the small values of flame size at this time suggest that some 'stretching' is taking place, which may be responsible for the reduced early flame growth rates calculated for triple injection. From observations, it is believed that the initial stretching is followed by some 'anchoring' of the flame to the electrode, and subsequent early flame growth wrapped around the spark plug with very little displacement overall. This may have negative effects of increased heat losses to the electrodes which are thought to cause quenching of the flame, particularly for leaner flames [25]. It is also possible however, that the triple injections result in a charge with very different fuel concentration field to that of single injection, which may be leaner around the spark plug at ignition timing in comparison to single injection. The latter may be manifested due to increased spray impingement on the spark electrode for single injection relative to triple injection that results in fuel staying closer to the electrodes and the crevices next to the ceramic insulator, fuelling the initial stages of flame growth with richer than stoichiometric mixture.

In contrast to Figure 27, Figure 28 quantifies the flame centroid displacement calculated for every crank angle degree along the path of movement and Figure 29 shows the same relationship relative to flame size. It is clear that triple injection is associated by only a marginally increasing centroid displacement with flame size, but the effect of initial flame stretch is implied by the higher gradient of the line in the first $5 \mathrm{~mm}$ radius of flame growth.

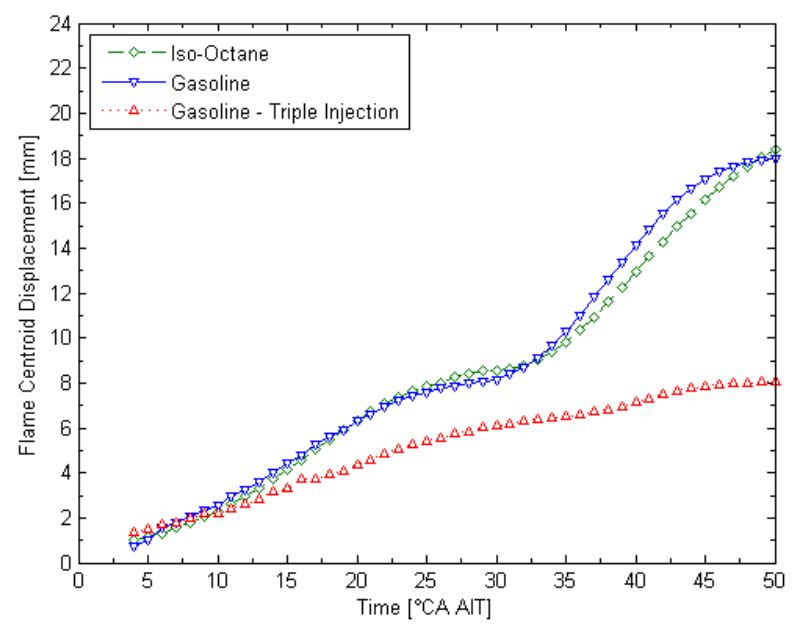

Figure 28. Flame Centroid Displacement (Path Length). 


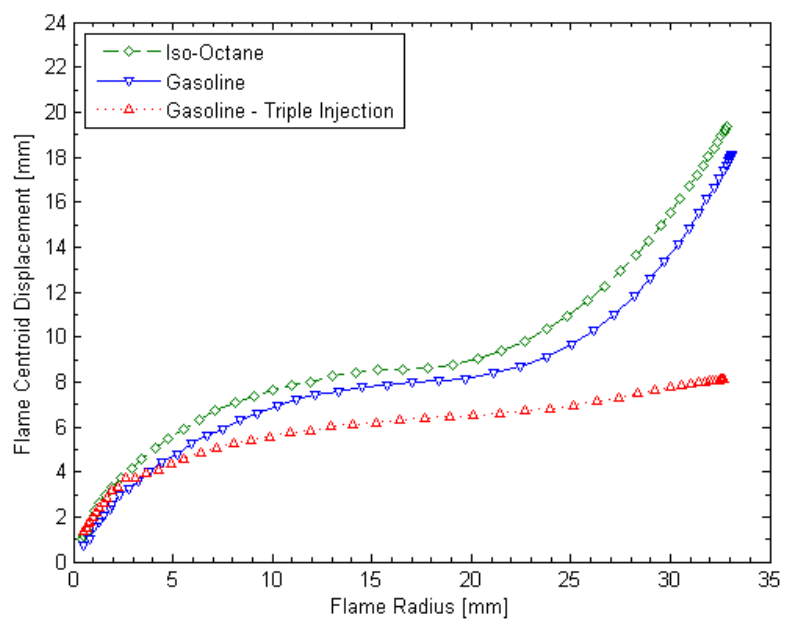

Figure 29. Relationship between Flame Centroid Displacement (Path Length) and Flame Size.

A 'global' centroid speed is also calculated by taking the flame displacement at any crank angle and dividing it by the time elapsed after ignition at that crank angle. As such it probably presents a centroid speed biased towards 'bulk' movement and essentially filters the effects of local smaller scale flow effects. This is shown in Figure 30 which shows that the global centroid speed is initially higher than that for single injection, by nearly 1 $\mathrm{m} / \mathrm{s}$. The magnitude of the centroid speed shown in Figure $30(\sim 3 \mathrm{~m} / \mathrm{s})$ is consistent with mean flow velocities measured by PIV in an identical engine at the same operating point [24].

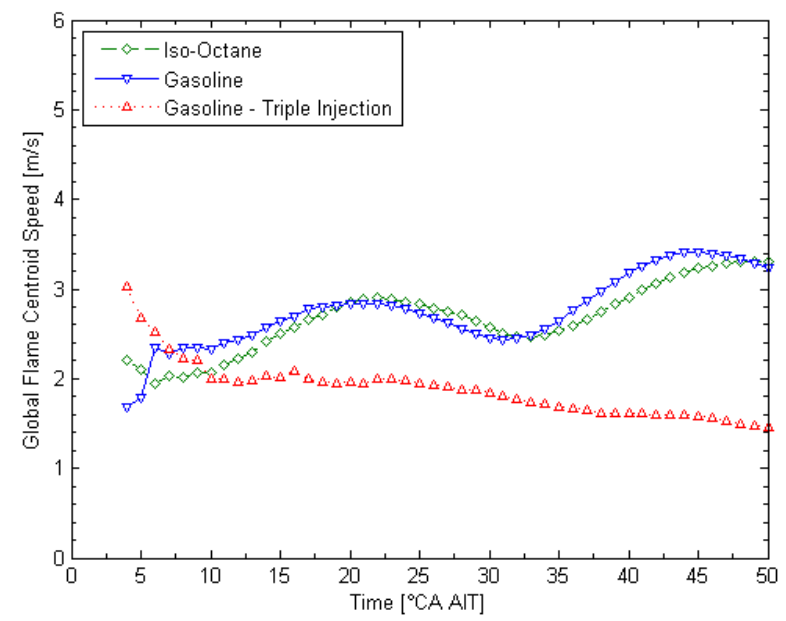

Figure 30. Global Flame Centroid Displacement Speed.

By calculating the change in flame centroid displacement with time, using a local 'central differencing' approach for every crank angle timing that the flame images were acquired at, the 'local' centroid speed is also obtained from Figure 28 which now reveals such previously masked effects of smaller scales on flame motion, especially at the early stages of flame growth. This relationship is shown in Figure 31 . The early flame growth phase $0-20^{\circ} \mathrm{CA}$ AIT is characterized by large changes in the local displacement speeds, with singleinjection iso-octane and single-injection gasoline showing very similar trends. The subsequent increase in centroid displacement speeds for single-injection gasoline and iso-octane after $30^{\circ} \mathrm{CA}$ AIT is a result of the flames expanding into the unburned regions on the intake side of the engine. This effect is also seen clearly in Figures 26 and 27 where the centroids travel towards the exhaust side and then change direction towards the middle of the combustion chamber as the flame front now moves across to the intake side.

Combustion with triple-injection gasoline does not follow the trends seen for single injection. The mean flame centroid is much more stable around the spark-plug electrode and indeed this is reflected in the smaller 'global' centroid speeds observed $(\sim 1.5-2 \mathrm{~m} / \mathrm{s}$ in Figure $31)$. This suggests that something has either happened to the flow-field or that the sensitivity of the initial kernels to convecting currents has totally changed, probably to a degree that flame growth has become independent of the flow field and perhaps only dictated by the local fuel concentration.

Measured flow velocities using PIV just below the spark plug in an identical engine [25] showed mean bulk flow velocities of $2-4 \mathrm{~m} / \mathrm{s}$ in the direction from the intake to the exhaust side. It may be hypothesized that for multiple injections, the increased spray-flow momentum transfer due to multiple 'pumping' of the flow during the critical 'valve jet' flow phase early in the cycle may partially neutralize the typical in-cylinder tumble flow such that bulk flame displacement is significantly reduced relative to the single-injection flame growth. Quite probable, however, is the reverse condition, where the higher momentum jet produced from the longer single injection, adds energy to the bulk flow such that during the compression stroke higher mean flow velocities are attained and survive to TDC. Measurements of the velocity field under motoring conditions without injection, as well as with single and multiple injections, would be useful in assessing the likelihood of such mechanisms and study how the gas-phase velocity field is affected by the injection event. Previous studies based on computational results suggest that there should be a measurable effect [32].

The plotting of flame centroid speeds versus flame radius in Figure 32 shows that although iso-octane and gasoline behave similarly, the respective flames are subjected to different 'stresses' during flame growth. In Figure 31 it can be seen that gasoline moves across the bore towards the intake side earlier than iso-octane, just before $30^{\circ} \mathrm{CA}$ AIT, with iso-octane lagging by $\sim 2^{\circ} \mathrm{CA}$. However, in terms of flame size, the flame centroid speed in Figure 32 shows that the iso-octane flame has a smaller size than that of gasoline, i.e. a similar flame motion is linked to a smaller flame which can essentially lead to different levels of flame stretch. 


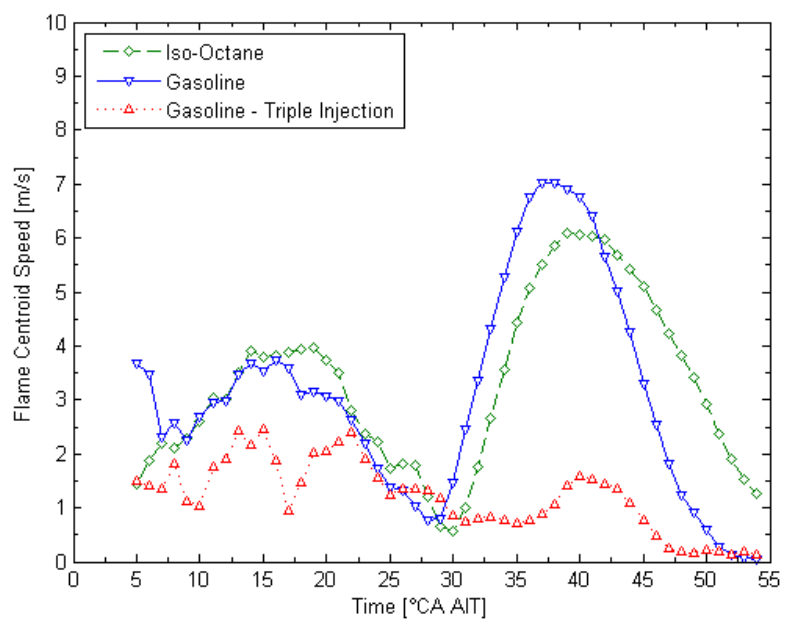

Figure 31. Local Flame Centroid Displacement Speed.

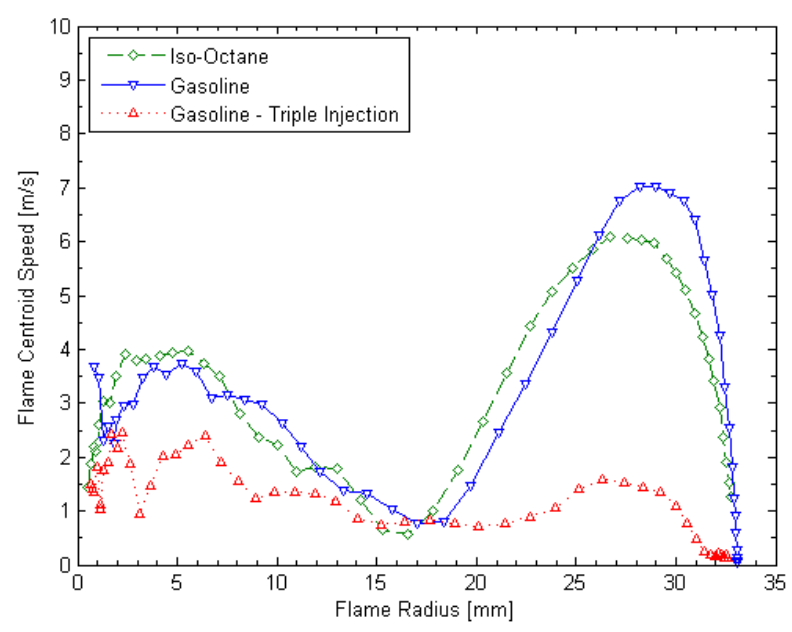

Figure 32. Relationship between Local Flame Centroid Displacement Speed and Flame Size.

\section{FLAME GROWTH VARIABILITY}

In this section gasoline single-injection flames are analyzed by conditionally averaging them with respect to their timing of $10 \%$ MFB $\left(\theta_{\mathrm{xb} 10 \%}\right)$. A definition of 'Good', 'Average' and 'Bad' cycles is then given to each cycle depending on its value of $\theta_{\mathrm{xb} 10 \%}$ relative to the mean and three groups of cycles are formed. The middle group is defined as 'Average' cycles and corresponds to cycles that have $\theta_{\mathrm{xb} 10 \%}$ equal to the mean $\theta_{\mathrm{Xb} 10 \%}$ plus or minus one standard deviation $\left(354^{\circ} \mathrm{CA} \leq \theta_{\mathrm{xb} 10 \%} \leq 358^{\circ} \mathrm{CA}\right.$ for the batch of cycles studied here), and the two other groups lie on either side of this middle group, i.e. with the 'Good' cycles having lower $\theta_{\mathrm{xb} 10 \%}$ than the mean $\theta_{\mathrm{xb} 10 \%}$ minus one standard deviation $\left(\theta_{\mathrm{xb} 10 \%}<354^{\circ} \mathrm{CA}\right)$ and the 'Bad' cycles having $\theta_{\mathrm{xb} 10 \%}$ higher than the mean $\theta_{\mathrm{xb} 10 \%}$ plus one standard deviation $\left(\theta_{\mathrm{xb} 10 \%}>358^{\circ} \mathrm{CA}\right)$. The conditionally-averaged results reveal a noticeable difference between 'Bad' cycle flame-centroid paths and 'Good' or 'Average' cycle flame-centroid paths in Figure 33. 'Good' or 'Average' flames tend to drift uniformly away from the spark plug than those of 'Bad' cycles, but 'Bad' cycles exhibit larger initial centroid displacements as shown in Figure 34. Figure 33 also shows how 'Bad' cycles change direction more times than 'Good' and 'Average' cycles, the latter tending to have a smoother and narrower centroid movement during full combustion duration.

The flame-centroid displacement speed is higher for 'Bad' cycles than for 'Good' or 'Average' cycles in the early stage of flame growth, either 'globally' in Figure 35 or 'locally' in Figure 36 (as distinguished earlier), suggesting that more rapid convection of the flame may be taking place, due to higher flow velocity. This may be causing a negative effect from excessive stretching of the flame, as the flames of 'Bad' cycles are also smaller. During the initial phase of $5-20^{\circ} \mathrm{CA}$ AIT, it is seen that 'Good' cycles are associated with a global centroid displacement speed of $1.5-2.5 \mathrm{~m} / \mathrm{s}$ (with a steady increase), whilst 'Bad' cycles are associated with speeds of the order $4 \mathrm{~m} / \mathrm{s}$ from the earliest stage of growth.

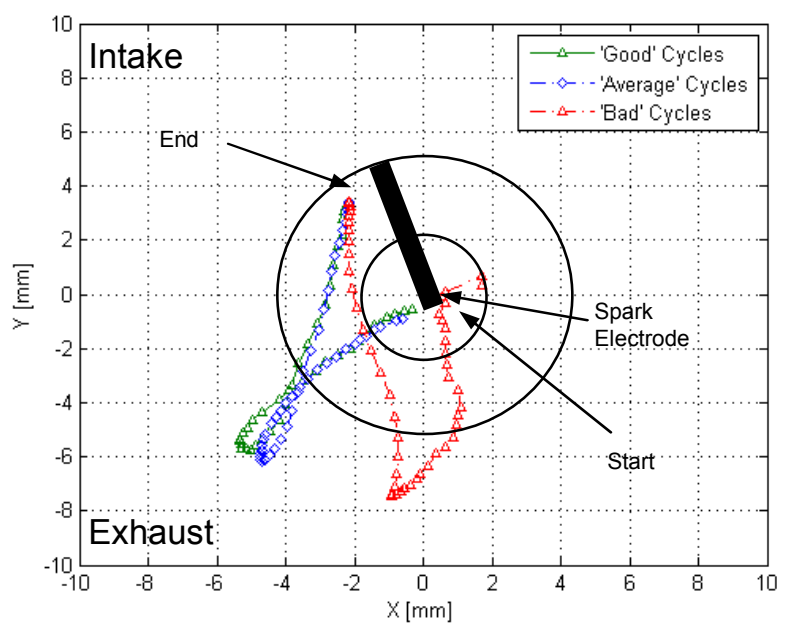

Figure 33. Conditionally-Averaged Flame Centroid Locations (4-60 6 CA AIT).

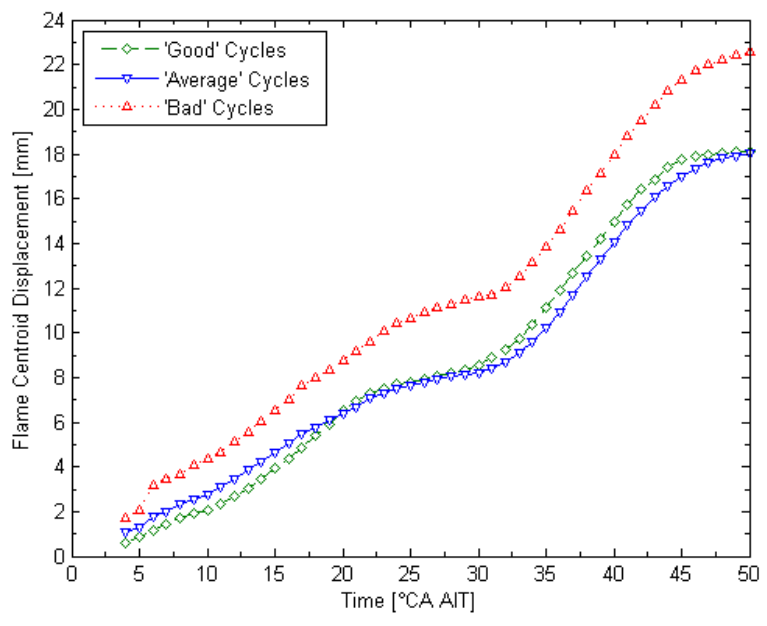

Figure 34. Conditionally-Averaged Flame Centroid Displacement (Path Length). 


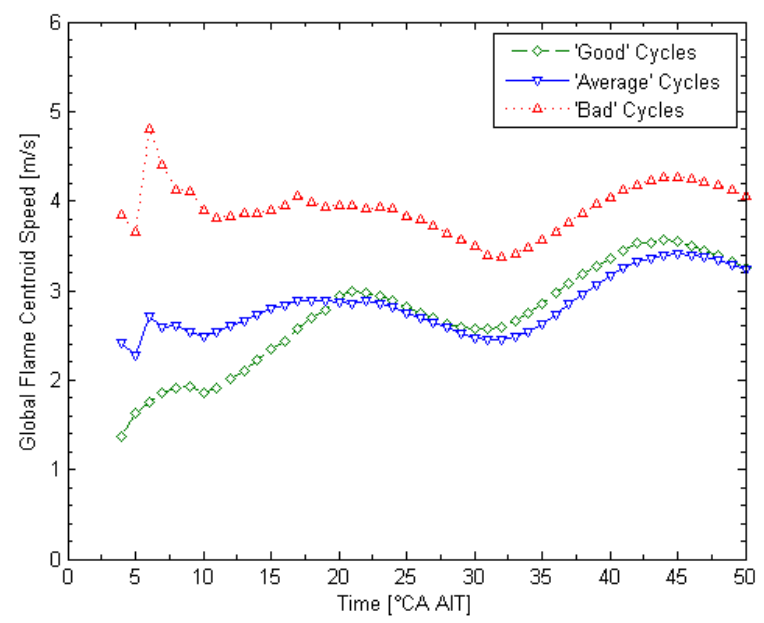

Figure 35. Conditionally-Averaged Global Flame Centroid Displacement Speed.

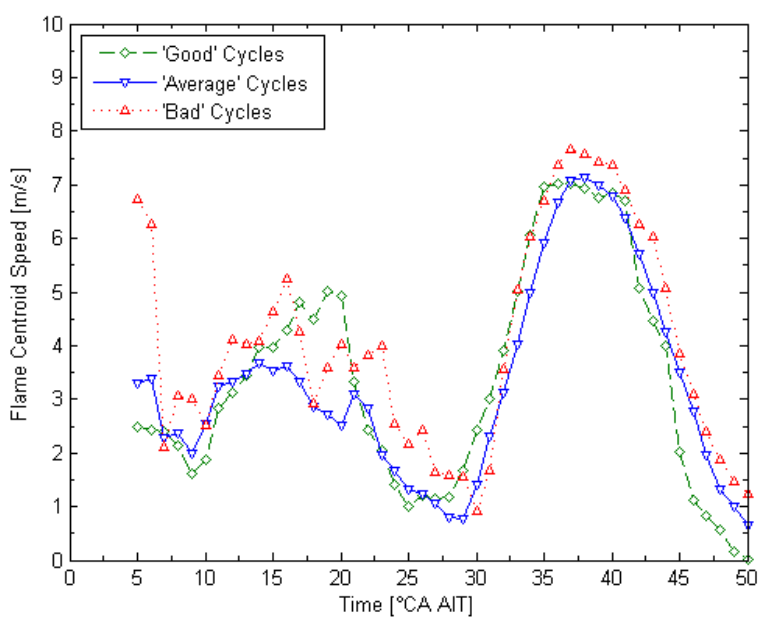

Figure 36. Conditionally-Averaged Local Flame Centroid Displacement Speed.

\section{CONCLUSIONS}

Time-resolved images of fuel spray development and flame growth were simultaneously acquired in an optical DISI engine. The injector was centrally-mounted with a multi-hole arrangement and the measurements were conducted for stoichiometric conditions with early injection strategies (in the range $60-80^{\circ}$ CA ATDC) with 0.5-1.0 bar intake pressure, focusing on the lower-load of 0.5 bar. The different behavior of single and multicomponent fuels (iso-octane and gasoline) was captured with different engine-coolant temperatures $\left(50^{\circ} \mathrm{C}\right.$ and 90 ${ }^{\circ} \mathrm{C}$ ) under motoring and firing conditions with a fixed spark advance of $35^{\circ} \mathrm{CA}$. Single and multiple injections per cycle were compared (three short injections at around the same timing to that of single injection).

The engine-coolant temperature was seen to have a more pronounced effect on spray formation with gasoline than with iso-octane. In the extreme, at $90{ }^{\circ} \mathrm{C}$ engine- coolant temperature, the gasoline spray was seen to partially collapse and produce a spray 'cloud' with a footprint directly below the injector nozzle, in effect reducing some of the directionality of the available multinozzle arrangement. Spray plumes with higher turning angles appeared to suffer less collapse, although this was not directly quantified. Iso-octane sprays never collapsed and retained good directionality even at $90{ }^{\circ} \mathrm{C}$. The three short injections of gasoline per cycle showed no obvious spray impingement on cylinder walls or on piston crown, as the longer single injections did. The triple-injection strategy also led to different flame growth.

Spray and flame areas were calculated from the images acquired through the piston crown and specific conclusions may be summarized as follows:

- The liquid-core spray area for gasoline was $10-15 \%$ lower for $90{ }^{\circ} \mathrm{C}$ than for $50{ }^{\circ} \mathrm{C}$ at the end of injection, as a result of higher evaporation at the spray-gas interfaces. The higher engine-coolant temperature also led to a faster reduction is spray areas after the end of injection. For iso-octane the effect of enginecoolant temperature on spray areas was marginal during injection but also resulted in faster reduction of spray areas in the post injection stage.

- The effect of engine firing on spray formation with 50 ${ }^{\circ} \mathrm{C}$ engine-coolant temperature was a reduction in the measured spray areas by $10-15 \%$ for iso-octane and $15-20 \%$ for gasoline. The rate of reduction in spray areas after the end of injection was higher for both fuels than that at motoring conditions, being more pronounced for gasoline. The effect of firing on the reduction of spray areas with fixed enginecoolant temperature $50{ }^{\circ} \mathrm{C}$ was overall stronger than the increase in engine-coolant temperature from 50 ${ }^{\circ} \mathrm{C}$ to $90{ }^{\circ} \mathrm{C}$ for motoring conditions.

- The peak RMS of spray areas (which can be considered as a measure of cyclic variability in liquid atomization and evaporation) was about $25 \%$ of the mean for iso-octane and $15 \%$ for gasoline under motoring conditions at the engine temperature of 50 ${ }^{\circ} \mathrm{C}$. Increasing the temperature to $90{ }^{\circ} \mathrm{C}$ decreased the peak RMS for iso-octane by $\sim 40 \%$ with respect to that at $50{ }^{\circ} \mathrm{C}$ which indicated more consistent evaporation on a cycle-by-cycle basis. The peak RMS for gasoline was relatively unaffected.

- Engine firing with $50{ }^{\circ} \mathrm{C}$ engine-coolant temperature led to a decrease in the peak RMS of spray areas for iso-octane by $20 \%$ with respect to that of motoring conditions. The peak RMS of spray areas for gasoline was again relatively unaffected.

- The triple-injection gasoline strategy resulted in flames of lower luminosity with a smaller number of bright spots than those seen for single injection. This may be associated with lower levels of soot. However, the variability in peak pressure was higher 
than that for single injection. Flame growth was very different to that with single injection, being more 'spherical' and 'centralized' at the spark plug. This was in contrast to single-injection flames which generally grew towards the exhaust side first. The direction of flame growth for single-injection isooctane was similar to that for single-injection gasoline, but peak pressure was lower and variability was higher, but not higher than that of triple-injection.

- Although clear differences were observed between the fuels and injection strategies for the fixed spark advance used, when individual cycles with similar timings of $50 \%$ mass fraction burned were compared, they showed similar $P_{\max }, \theta_{\mathrm{Pmax}}$ and flame growth rates. This indicated that with optimization of the ignition timing, triple-injection gasoline could achieve similar 'performance' to the single-injection.

- The mean flame centroid displacement speed for single injection agreed with the expected mean flow velocity field around ignition timing $(\sim 3 \mathrm{~m} / \mathrm{s})$. Flames with triple-injection strategy showed much lower displacement from the spark plug, as well as lower flame centroid displacement speed that did not agree with the expected magnitude of the mean flow at ignition timing. This may be associated with a different flow-field at ignition timing with this injection strategy as a result of different spray-flow interactions during the injection process itself (e.g. from direct effects of the injection shots themselves on the flow field) that lead to different bulk motion and mixture formation (e.g. different homogeneity).

- Single-injection gasoline flames of cycles with slow rates of heat release were found to follow a noticeably different path of motion during growth than those with faster rates of heat release. These cycles were also associated with larger flamecentroid displacement speeds from ignition timing and throughout the full combustion process. The mechanism behind this observation is not clear but may be associated with different levels of stretch experienced by the flame on a cycle-by-cycle basis.

\section{ACKNOWLEDGMENTS}

The authors would like to thank Roger Cracknell and Harold Walmsley at Shell Global Solutions (UK) Ltd. for fuel supplies, technical and financial support and Jaguar Advanced Powertrain Engineering for injector supplies and continued technical and financial support, as well as the Engineering and Physical Sciences Research Council (EPSRC) in the UK for financial support under grant GR/S58850/01.

\section{REFERENCES}

1. Ozdor, N., Dulger, M. and Sher, E., "Cyclic Variability in Spark Ignition Engines - A Literature Survey", SAE Paper 940987, 1994.
2. Aleiferis, P.G., Taylor, A.M.K.P, Whitelaw, J.H., Ishii, K. and Urata, Y., "Cyclic Variations of Initial Flame Kernel Growth in a Honda VTEC-E Lean-Burn SparkIgnition Engine", SAE Paper 2000-01-1207, 2000.

3. Aleiferis, P.G., Taylor, A.M.K.P., Ishii, K. and Urata, Y., "The Nature of Early Flame Development in a Lean-Burn Stratified-Charge Spark-Ignition Engine", Combustion and Flame, Vol. 136, pp. 283-302, 2004.

4. Aleiferis, P.G., Taylor, A.M.K.P., Ishii, K. and Urata, Y., "The Relative Effects of Fuel Concentration, Residual Gas Fraction, Gas Motion, Spark Energy and Heat Losses to the Electrodes in a Lean-Burn Spark-Ignition Engine", Journal of Automobile Engineering (Proceedings of IMechE, Part D), Vol. 218, pp. 411-425.

5. Aleiferis, P.G., Hardalupas, Y., Taylor, A.M.K.P., Ishii, K. and Urata, Y., "Flame Chemiluminescence Studies of Cyclic Combustion Variations and Air-toFuel Ratio of the Reacting Mixture in a Lean-Burn Stratified-Charge Spark-Ignition Engine", Combustion and Flame, Vol. 136, pp. 72-90.

6. Castagne, M., Dumas, J.P., Henriot, S. and Pierre, P., "Use of Advanced Tools for the Analysis of Gasoline Direct Injection Engines", Oil and Gas Science and Technology, Rev. IFP, Vol. 58, pp.79100, 2003.

7. Fujikawa, T., Nomura, Y., Hattori, Y., Kobayashi, T. and Kanda, M., "Analysis of Cycle-by-Cycle Variation in a Direct-Injection Gasoline Engine Using a LaserInduced Fluorescence Technique", International Journal of Engine Research, Vol. 4, pp.143-153, 2003.

8. Itoh, T., Kakuho, A., Hiraya, K., Takahashi, E. and Urushihara, T., "Quantitative analysis of Mixture Preparation Processes in New Direct-Injection Spark Ignition Engines", JSME International Journal, Series B, Vol.18, pp.679-686, 2005.

9. Smith, J.D., Sick, V., "A Multi-Variable High-Speed Imaging Study of Ignition Instabilities in a SprayGuided Direct-Injected Spark-Ignition Engine", SAE Paper 2006-01-1264, 2006.

10. Kashdan, J., Cherel, J. and Thirouard, B., "Particulate Matter and Hydrocarbon Emissions Measurements: Comparing First and Second Generation DISI with PFI in Single Cylinder Optical Engines", SAE Paper 2006-01-1262, 2006.

11. Turner, J.W.G., Pitcher, G., Burke, P., Garner, C.P., Wigley, G., Stansfield, P., Nuglisch, H.J., Ladommatos, N., Patel, R. and Williams, P., "The HOTFIRE Homogeneous GDI and Fully Variable Valve train Project - An Initial Report", SAE Paper 2006-01-1260, 2006.

12. Suzuki, Y., Oki, H. and Kurosawa, S., "Gasoline S.I. Engine Combustion and Knocking Analysis on the Mixture Formation in the Various Direct Injection Fuel Spray Patterns", SAE Paper 2006-01-0230, 2006.

13. Gandhi, A.H., Weaver, C.E., Curtis, E.W. Alger, T.F., Anderson, C.L. and Abata, D.L., "Spray Characterization in a DISI Engine during Cold Start: (1) Imaging Investigation", SAE Paper 2006-011004, 2006.

14. Gandhi, A.H., Weaver, C.E., Curtis, E.W. Alger, T.F., Anderson, C.L. and Abata, D.L., "Spray 
Characterization in a DISI Engine during Cold Start: (2) PDPA Investigation", SAE Paper 2006-01-1003, 2006.

15. Price, P., Stone, R., Collier, T. and Davies, M.T., "Particulate Matter and Hydrocarbon Emissions Measurements: Comparing First and Second Generation DISI with PFI in Single Cylinder Optical Engines", SAE Paper 2006-01-1263, 2006.

16. Li, J., Huang, Y., Alger, T.F., Mathews, R.D., Hall, M.J., Stanglmaiser, R.H., Roberts, C.E., Dai, W. and Anderson, R.W., "Liquid Fuel Impingement on InCylinder Surfaces as a Source of Hydrocarbon Emissions from Direct Injection Gasoline Engines", Journal of Engineering for Gas Turbines and Power, Vol. 123, pp. 659-668, 2001.

17. Zhao, F., Lai, M.C. and Harrington, D., "Automotive Spark-Ignited Direct Injection Gasoline Engines", Progress in Energy and Combustion Science, Vol. 25, pp. 437-562, 1999.

18. Nauwerck, A., Pfeil, J., Velji, A., Spicher, U. and Richter, B., "A Basic Experimental Study of Gasoline Direct Injection at Significantly High Injection Pressures", SAE Paper 2005-01-0098, 2005.

19. van Romunde, Z. and Aleiferis, P.G., "Effect of Operating Conditions and Fuel Volatility on Development and Variability of Sprays from Gasoline Direct Injection Multi-Hole Injectors", Atomization and Sprays, in Press, 2007.

20. van Romunde, Z., Aleiferis, P.G., Cracknell, R.F. and Walmsley, H.L., "Effect of Fuel Properties on Spray Development from a Multi-Hole DISI Engine Injector", SAE 2007 Powertrain and Fluid Systems Conference and Exhibition, October 29-31, Chicago, USA, SAE Paper 2007-01-4032, 2007.

21. Ozdor, N., Dulger, M. and Sher, E., "An Experimental Study of the Cyclic Variability in Spark Ignition Engines", SAE Paper 960611, 1996.

22. Alger, T., Mangold, B., Mehta, D. and Roberts, C., "The Effect of Spark Plug Design on Initial Flame Kernel Development and Spark Plug Performance" SAE Paper 2006-01-0224, 2006.

23. Mitroglou, N., Arcoumanis, C., Mori, K. and Motoyama, Y., "Mixture Distribution in a Multi-Valve Twin-Spark Ignition Engine Equipped with HighPressure Multi-Hole Injectors", $2^{\text {nd }}$ International Conference on Optical and Laser Diagnostics (ICOLAD) 2005, Journal of Physics: Conference Series, Vol. 45. pp. 46-58, 2005.

24. Jarvis, S., Justham, T., Clarke, A., Garner, C.P., Hargrave, G.K., Richardson, D., "Motored SI IC Engine In-Cylinder Flow Field Measurement Using time Resolved Digital PIV for Characterisation of Cyclic Variation”, SAE Paper 2006-01-1044, 2006.

25. Justham, T., "Cyclic Variability of Engine Intake and In-Cylinder Flows" PhD Thesis, Loughborough University, Wolfson School of Mechanical and Manufacturing Engineering, UK, in Preparation, 2007.

26. Myong, K., Motoyuki, A., Tomoyuki, T., Sends, J. and Fujimoto, H., "An Experimental Investigation and Numerical Analysis of Multi-Component Fuel Spray", JSME International Journal, Series B, Vol. 47, pp. 200-206, 2004.
27. Gilles-Birth, I., Bernhardt, S., Spicher, U. and Rechs, M., "A Study of the In-Nozzle Flow Characteristics of Valve Covered Orifice Nozzles for Gasoline Direct Injection", SAE Paper 2005-01-3684, 2005.

28. Li, T., Nishida K., Zhang, Y., Onoe, T. and Hiroyau, $\mathrm{H}$., "Enhancement of Stratified Charge for DISI Engines through Split Injection", JSME International Journal, Series B, Vol. 48, pp. 687-694, 2005.

29. Arndt, S., Gartung, K. and Brüggemann, D., "Spray Structure of High Pressure Gasoline Injectors: Analysis of Transient Spray Propagation and SprayGas Momentum Transfer", ILASS-Europe, Zurich, 2001.

30. Wright, J.H. and Drallmeier, J.A., "Cyclic Variability of Pulsed Spray Vapor Fields", Experiments in Fluids, Vol. 25, pp. 329-336, 1998.

31. Yang, J., Yi, J. and Anderson, W., "Simulation of the Effect of Wakes behind Fuel Droplets on Fuel Vapor Diffusion in Direct-Injection SI Engines", $4^{\text {th }}$ International Symposium COMODIA 98, p. 323, 1998.

32. Suh, E.S. and Rutland, C.J., "Numerical Study of Fuel/Air Mixture Preparation in a GDI Engine", SAE Paper 1999-01-3657, 1999.

\section{ABBREVIATIONS}

$\begin{array}{ll}\text { AIT } & \text { After Ignition timing } \\ \text { ASOI } & \text { After Start Of Injection } \\ \text { ATDC } & \text { After intake Top Dead Centre } \\ \text { EOF } & \text { End Of Fuel } \\ \text { EVC } & \text { Exhaust Valve Closure } \\ \text { EVO } & \text { Exhaust Valve Open } \\ \text { IMEP } & \text { Indicated Mean Effective Pressure } \\ \text { IVC } & \text { Intake Valve Closure } \\ \text { IVO } & \text { Intake Valve Open } \\ \text { MFB } & \text { Mass Fraction Burned } \\ \text { PIV } & \text { Particle Image Velocimetry } \\ \text { RMS } & \text { Root Mean Square } \\ \text { SOI } & \text { Start Of Injection } \\ \text { SOF } & \text { Start Of Fuel } \\ \text { TDC } & \text { Top Dead Centre } \\ \text { WOT } & \text { Wide Open Throttle } \\ \text { WWMP } & \text { World Wide Mapping Point }\end{array}$

\section{SYMBOLS}

$P_{\max } \quad$ Maximum In-Cylinder Pressure

$\theta_{P_{\max }} \quad$ Crank Angle of Occurrence of $P_{\max }$

$\theta_{\mathrm{xb} 10 \%} \quad$ Crank Angle of Occurrence of $10 \%$ MFB

\section{CONTACT}

Author for correspondence:
Dr. Pavlos Aleiferis
Department of Mechanical Engineering
University College London
Torrington Place
London WC1E 7JE
United Kingdom
E-mail: p_aleiferis@meng.ucl.ac.uk 